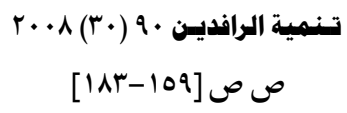

هل أن أسواق القمح العالمية غير تنافسية؟(")

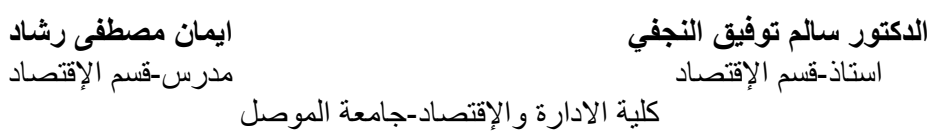

Salimalnajafy@yahoo.com

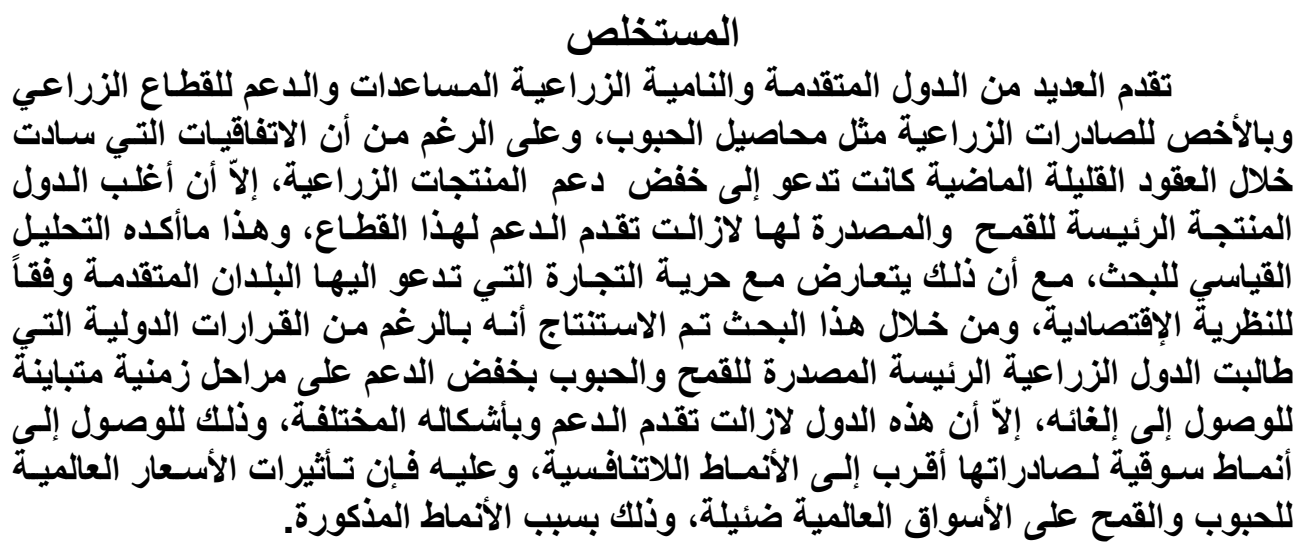

\title{
Are the International Wheat Markets Uncompetitive?
}

\author{
Salim T. Al - Najafi (PhD) \\ Professor \\ Department of Economics \\ University of Mosul
}

\author{
Iman M. Rashad (PhD) \\ Lecturer \\ Department of Economics \\ University of Mosul
}

\begin{abstract}
Several advanced and developing agricultural countries seek to introduce aids and supports to the agricultural sector; particularly, agricultural exports such as grain crops. Despite of the conventions prevailed during the few past decades which were calling to reduce support for agricultural products; most of the main grain producing countries are still backing up this sector in many means which have been confirmed by standard analysis. Despite the fact, it may contradict the freedom of commerce, which is being called by advanced counties in terms of modern economic theory. The study has concluded that

$$
\begin{aligned}
& \text { (") بحث مستل من أطروحة الدكتور اه الموسومة " تقدير وتحليل محددات العرض العالمي للحبوب }
\end{aligned}
$$

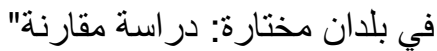

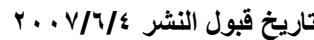

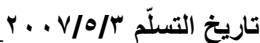




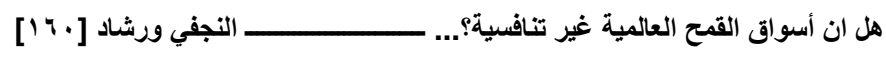

though the international resolutions that are calling various main grain exporting countries to reduce support along various periods of time until be abolished. However, these countries are still supporting this sector and provide it with different facilities - especially for export - in order to reach marketing forms for its exports that are closer to the uncompetitive types as well as the means they are closer to the monopoly of the minority. Thus, the impacts of wheat world prices on international markets are slim due to aforementioned types.

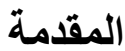

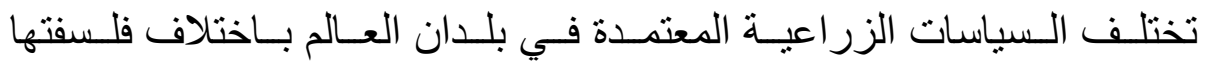

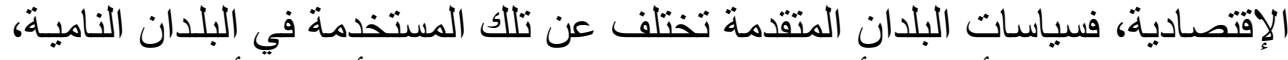

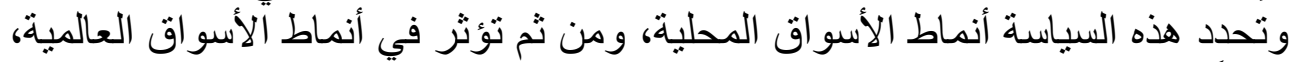

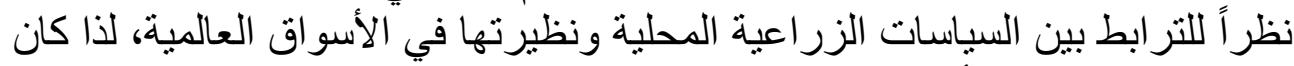

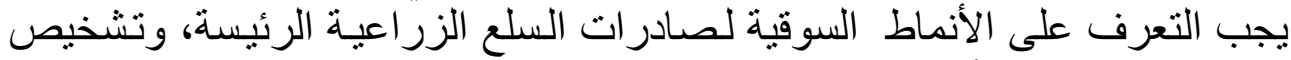

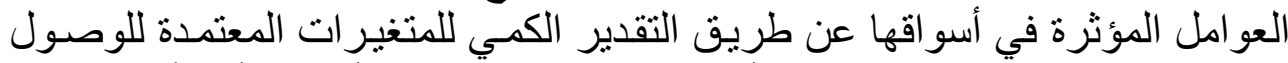

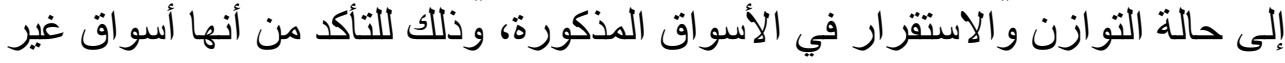

وقد جاءت أهمية البحث من أن السياسات الزر اعيـة المتبعـة من قبل البلدان

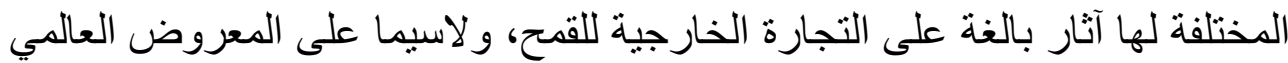

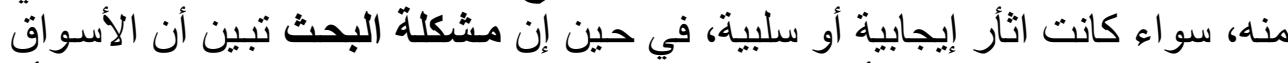

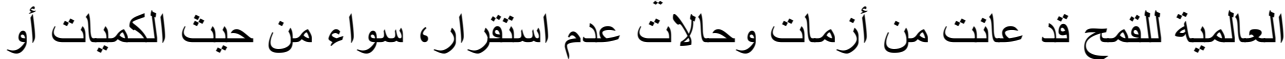

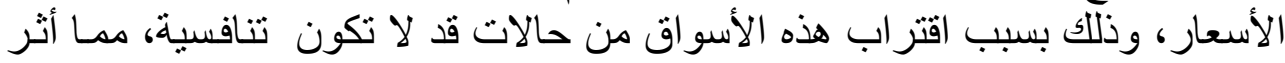

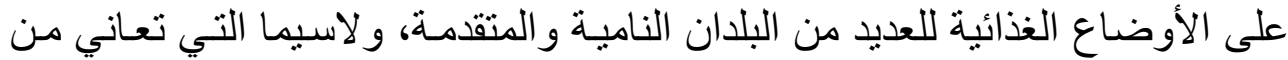

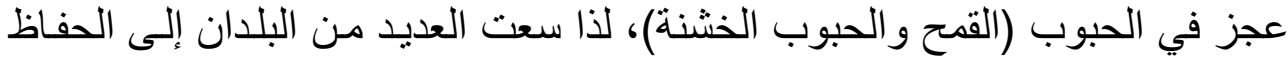

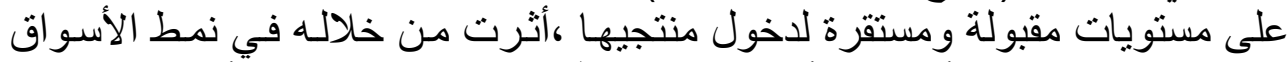

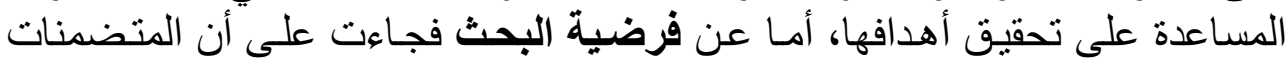

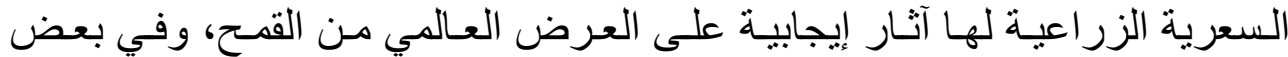

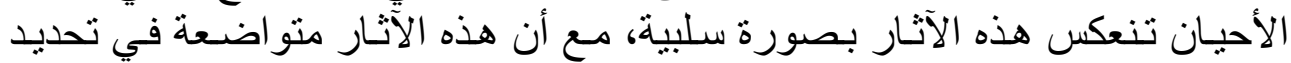

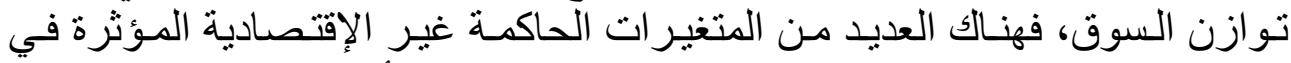

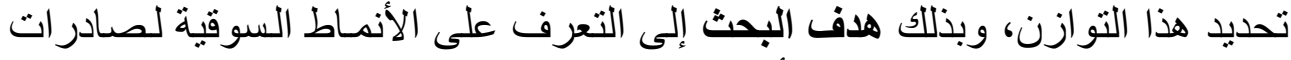

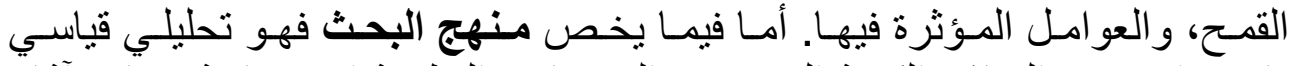

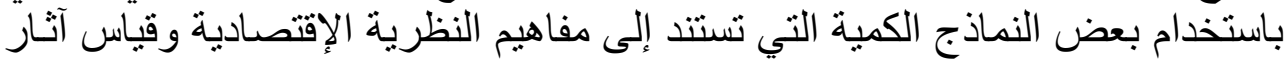

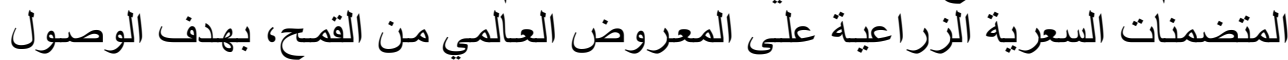

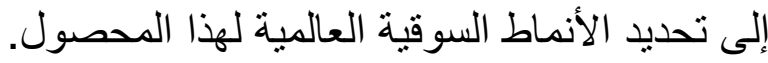




\section{ا ـ الطور العلاقات الإقتصادية الزراعية الدولية

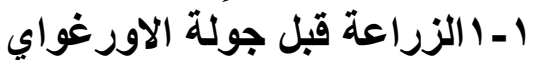

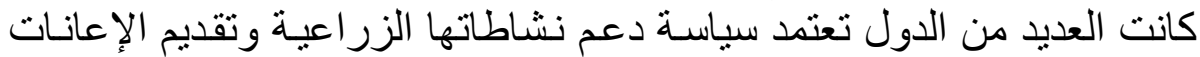

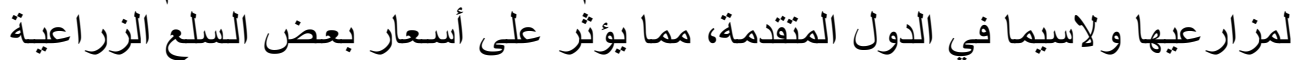

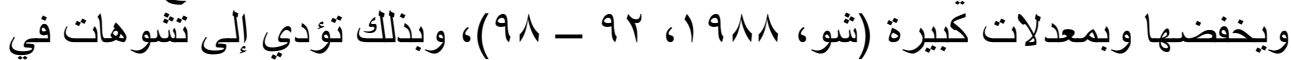

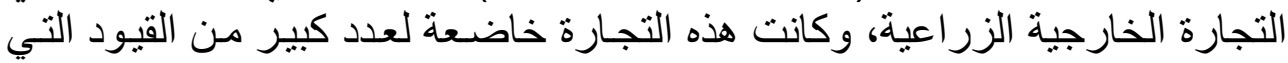

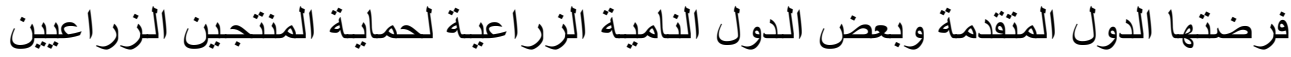

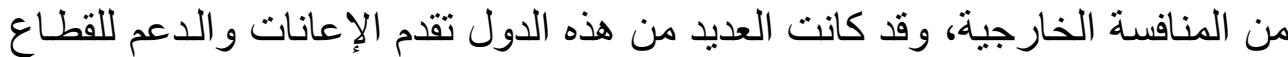

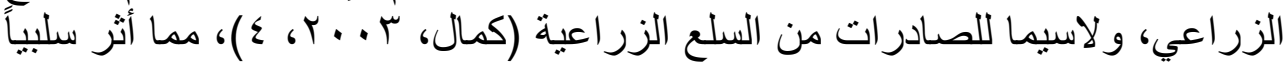

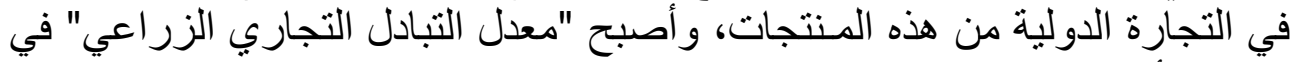

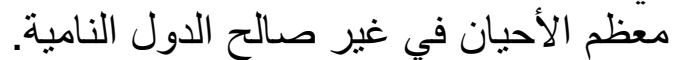

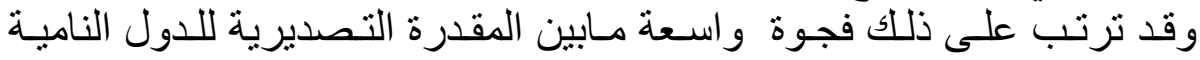

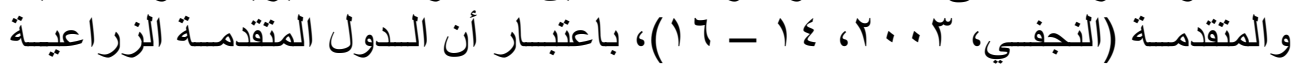

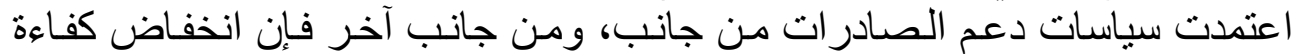

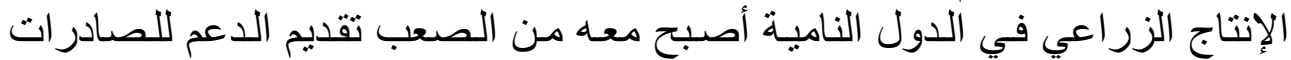

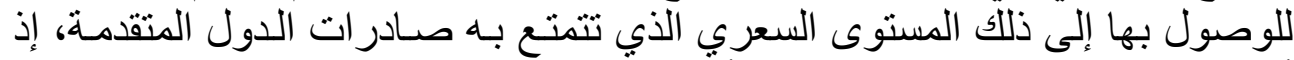

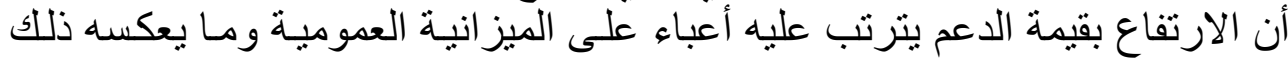

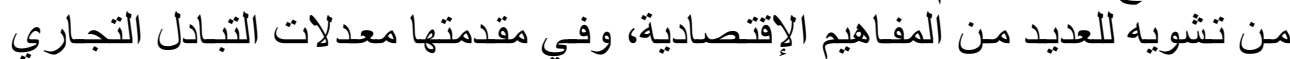

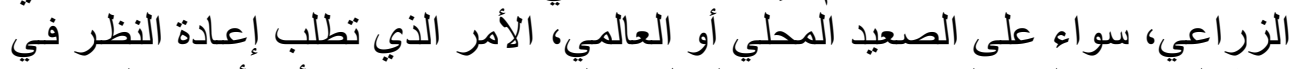

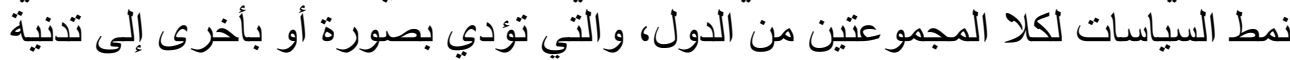

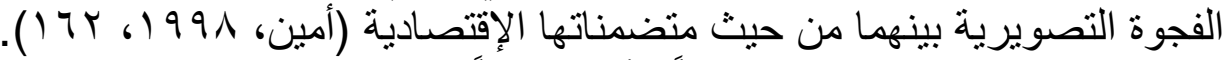

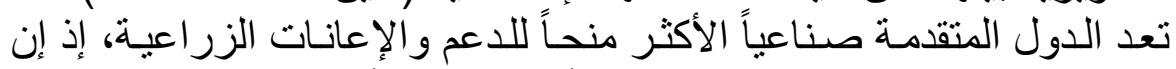

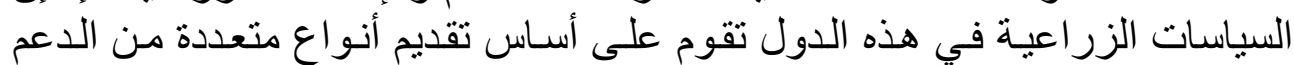

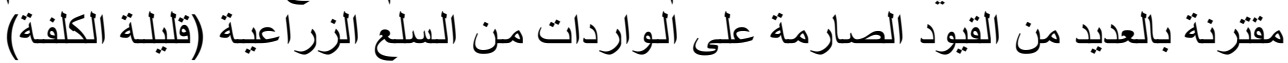

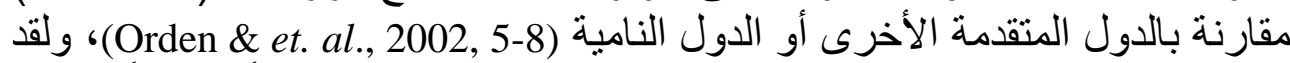

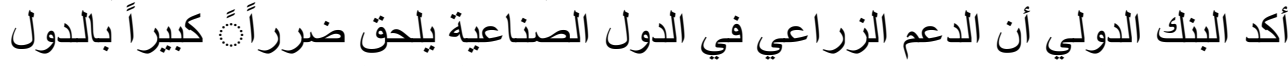

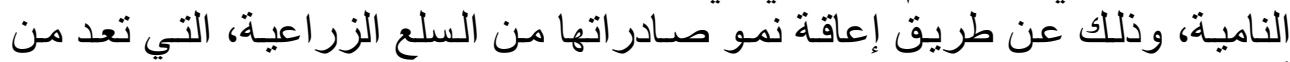

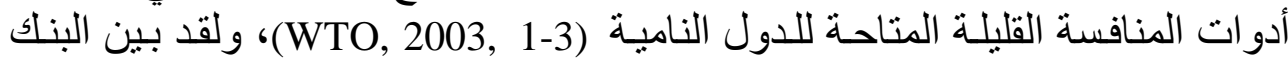

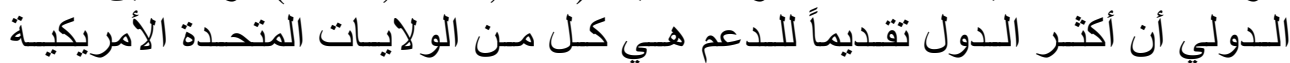

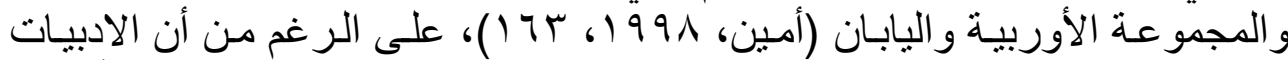

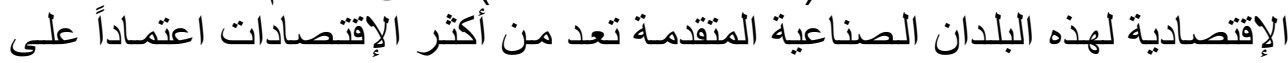

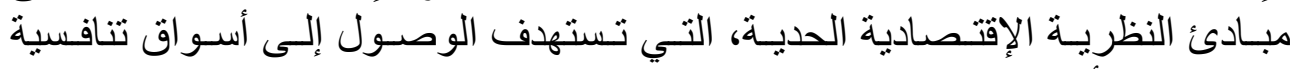

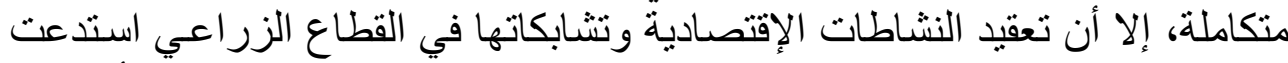

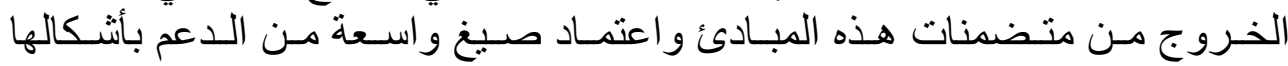




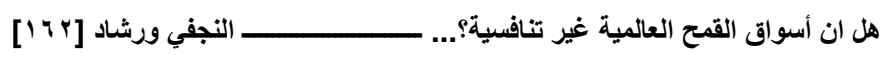

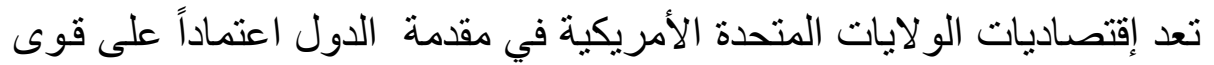

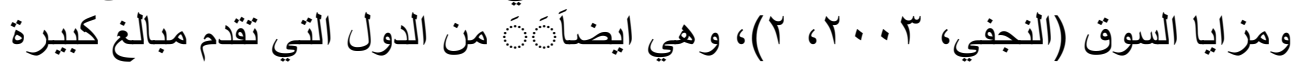

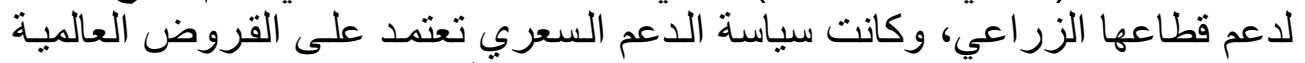

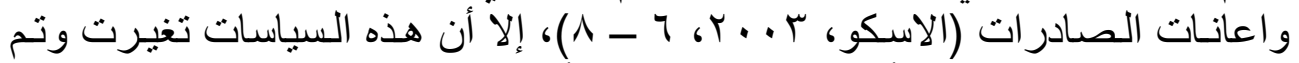

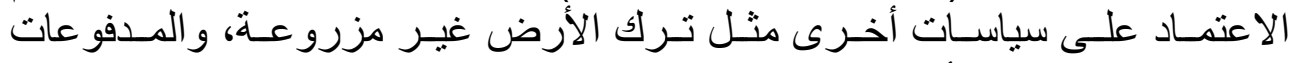

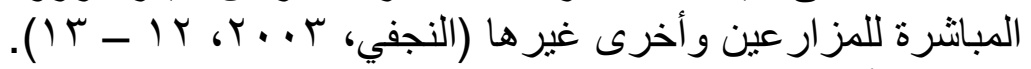

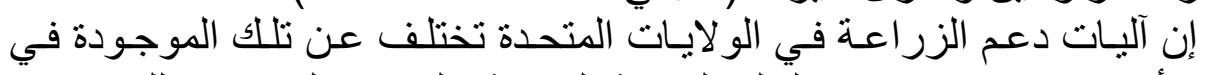

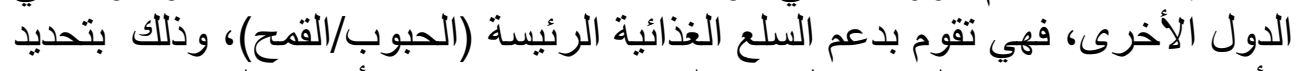

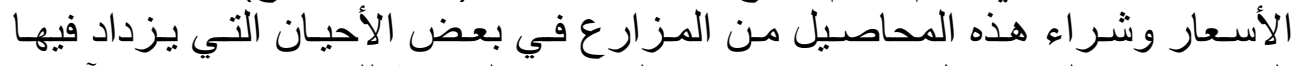

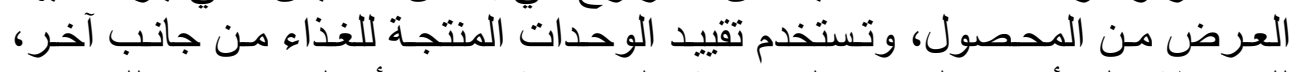

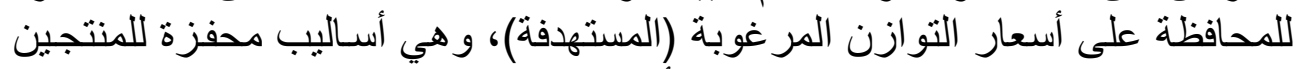

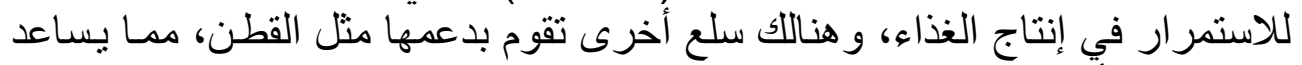

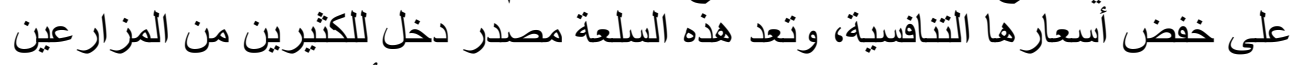

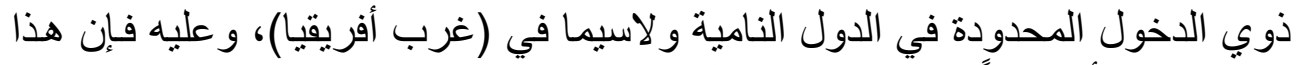

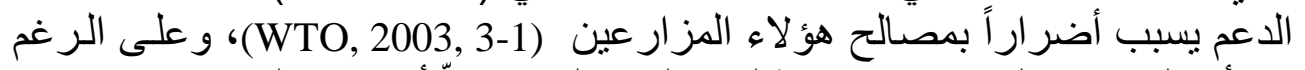

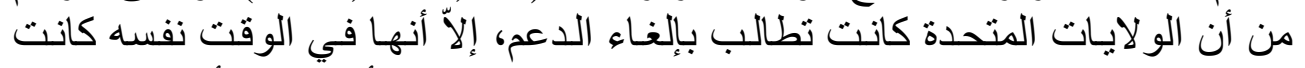

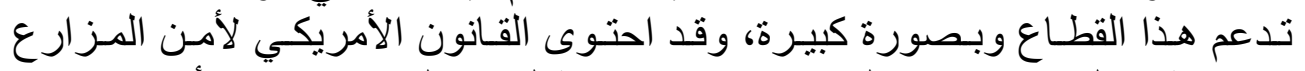

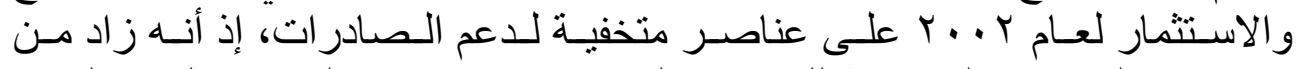

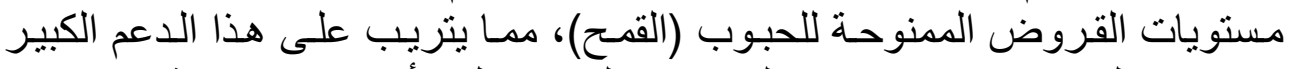

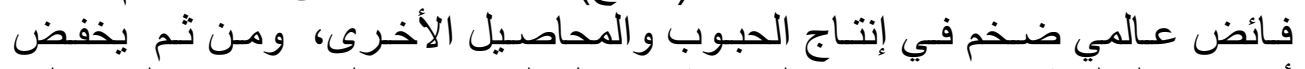

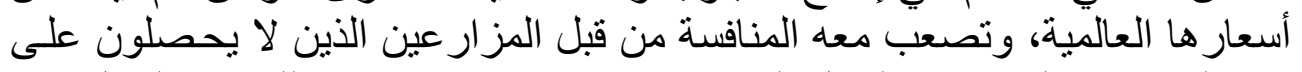

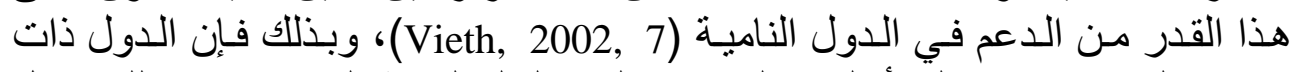

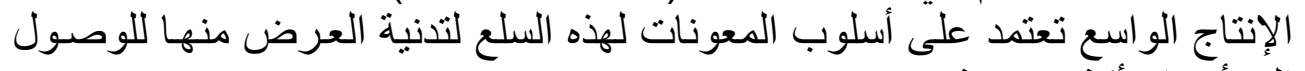
إلى أسعار أكثر ربحية.

\section{ثانياًٍ - المجموعة الأوربية}

اعتمدت المجموعة الأوربية على سياسات الدعم السعري، وحمايـة المنتجـات

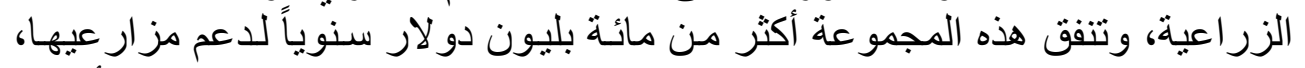

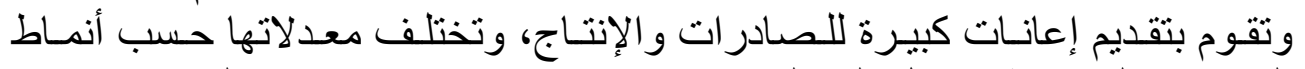

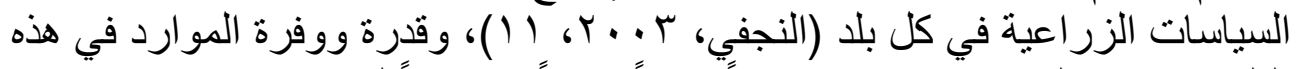

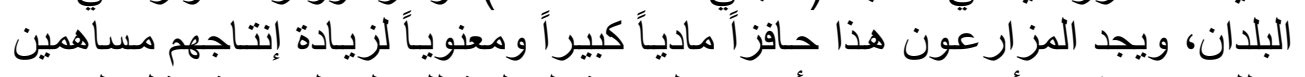

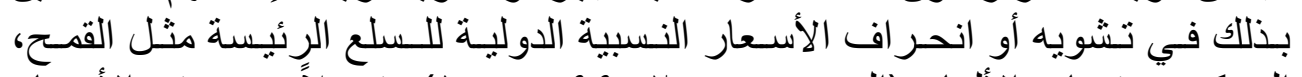

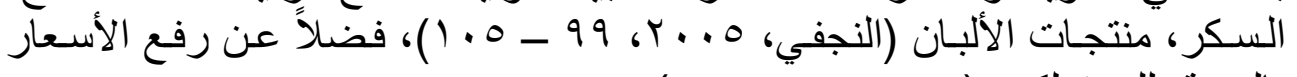
بالنسبة للمستهلكين (Maene, 2000, 4-9). 


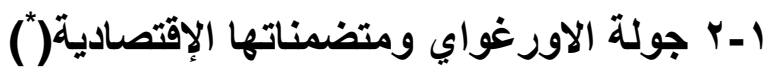

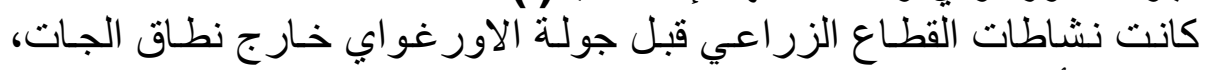

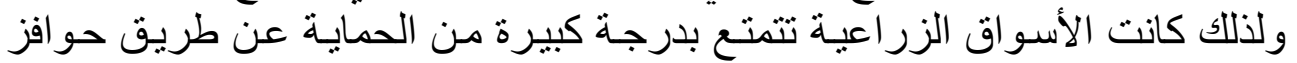

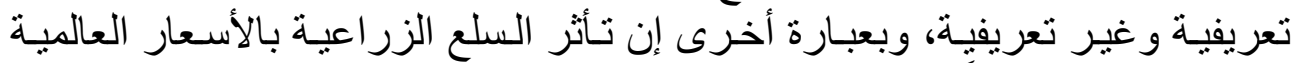

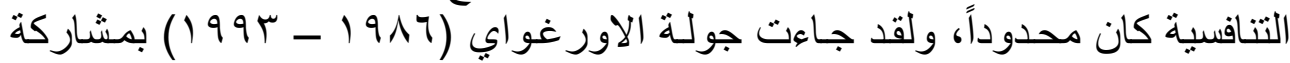

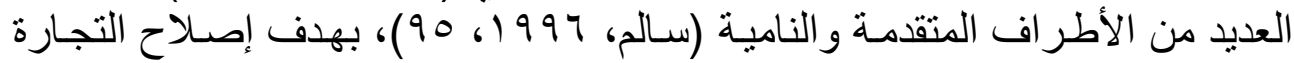
في القطاع الزر اعي وقطاع الخدمات (صندوق النقات العربي،

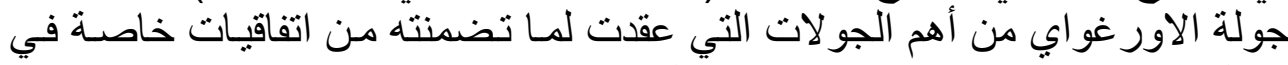

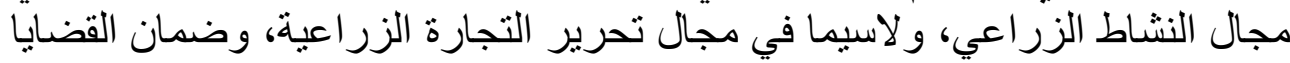

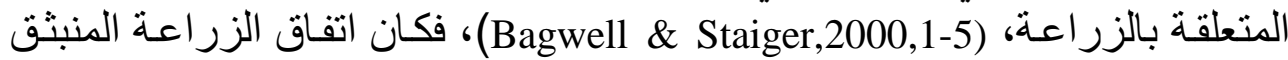

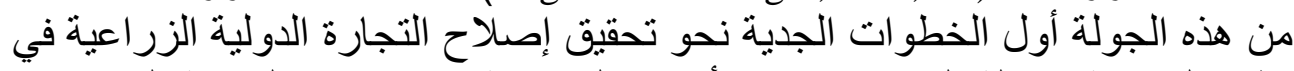

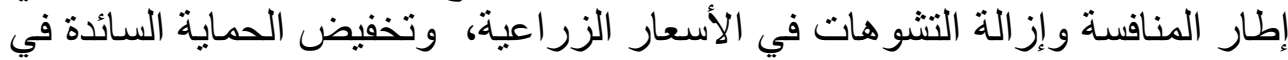

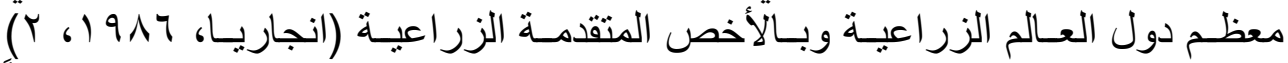

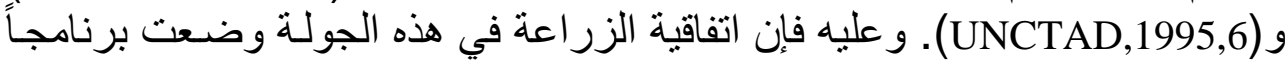

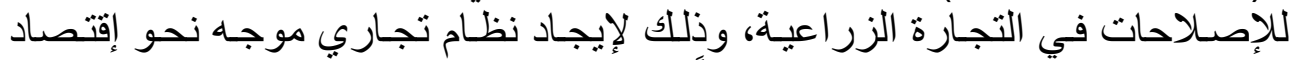

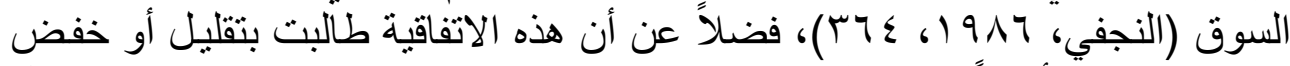

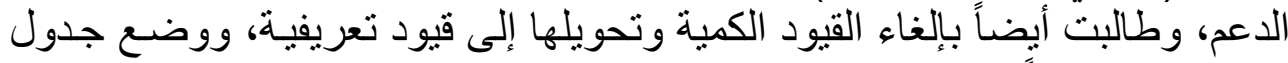

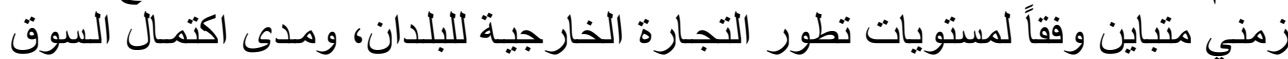

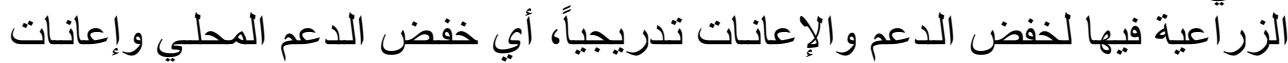

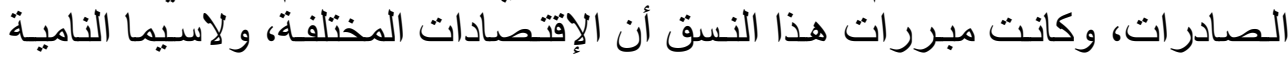

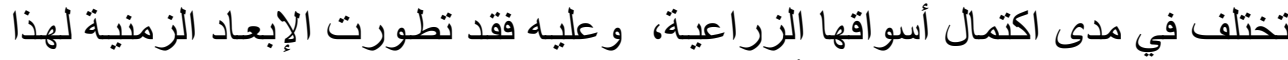

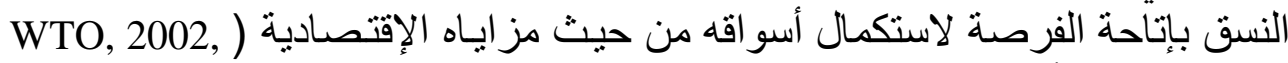

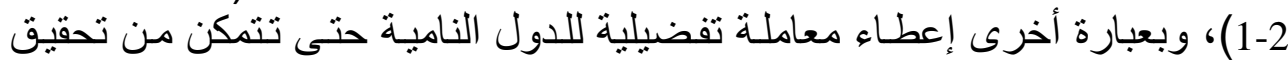

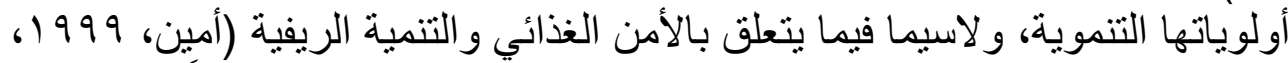

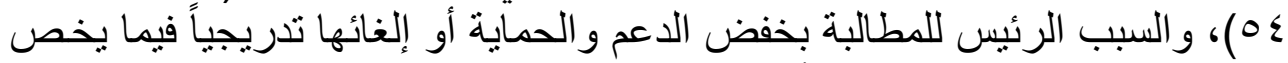

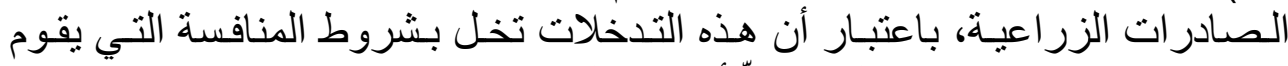

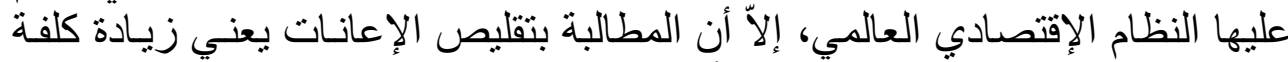

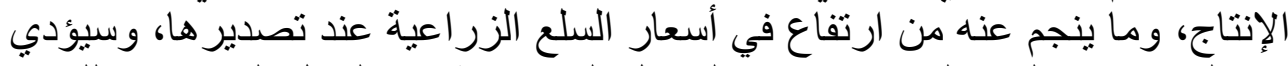

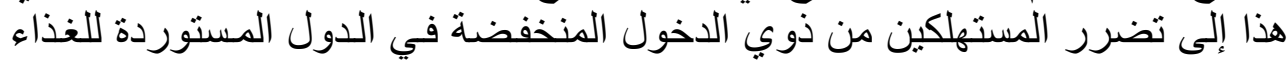
(نعوش، ؟ ـ . r، ع )، ويؤدي من إلى حالات إنعدام الأمن الغذائي.

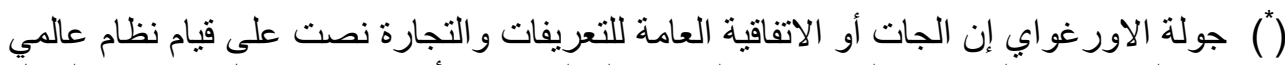

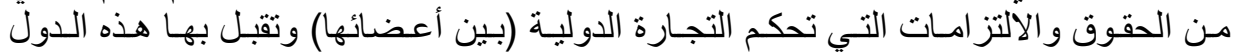

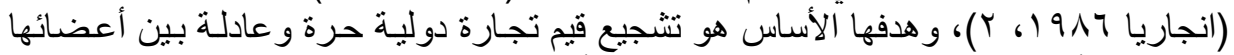

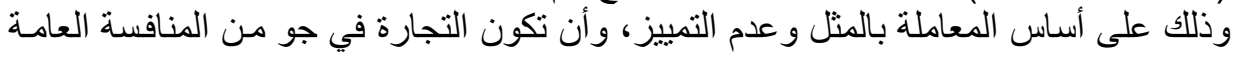

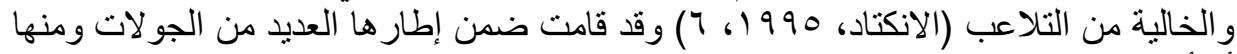

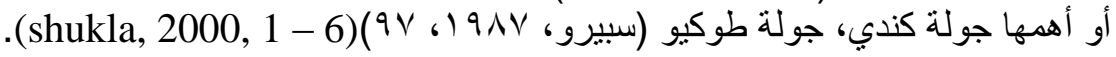




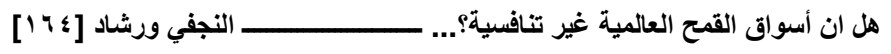

ويمكن القول إن هذه الاتفاقيات كانت لها آثنار إيجابيـة على التجـارة الزر اعبـة التية

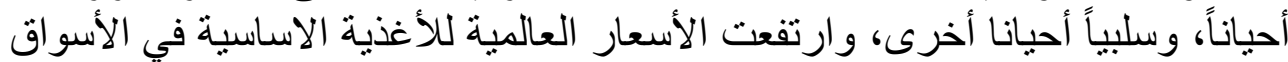

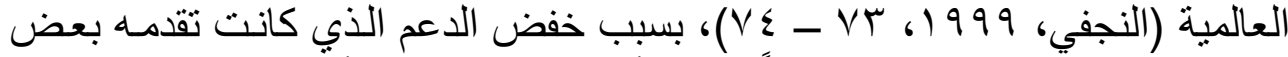

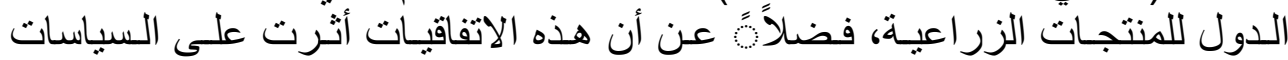

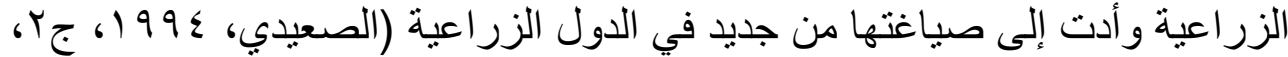

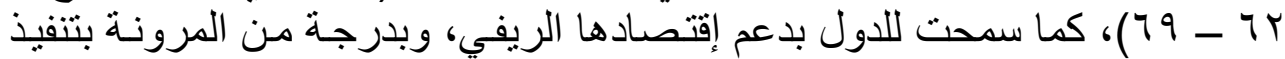

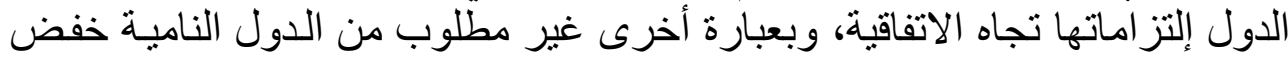

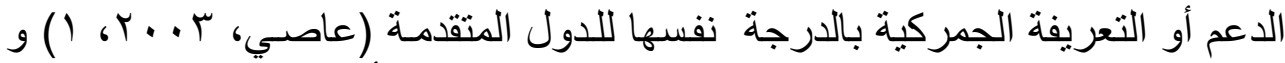

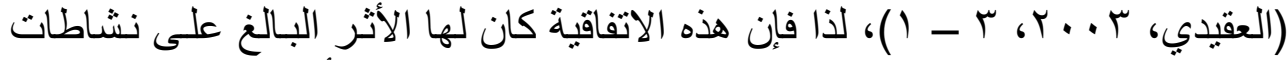

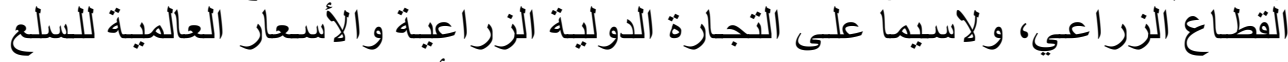

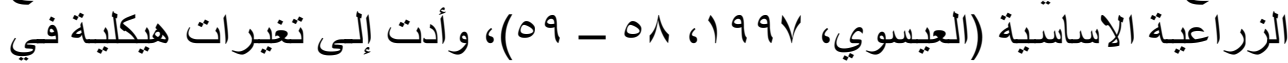

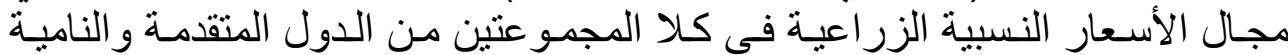

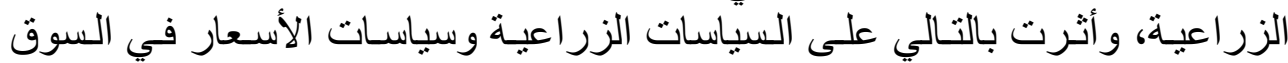

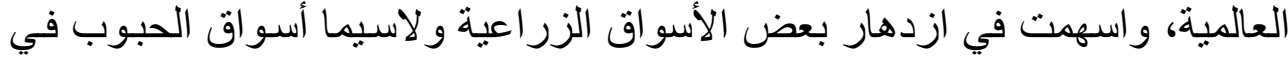

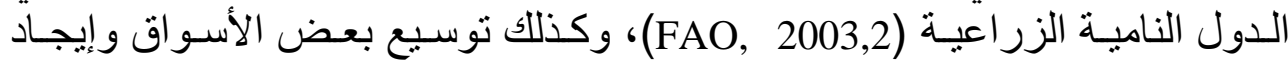

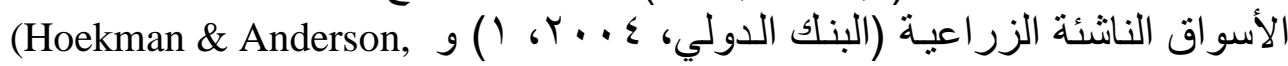

I-r الزراعة بعد جولة الاورغواي

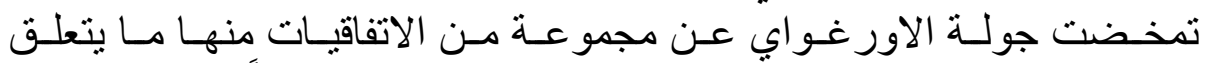

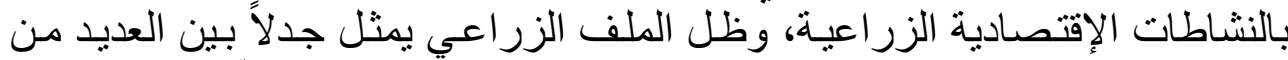

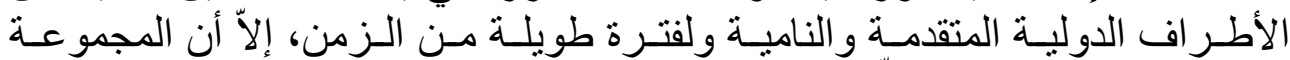

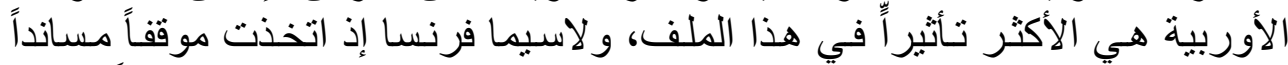

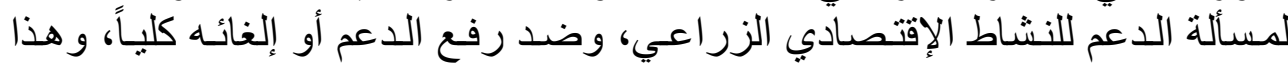

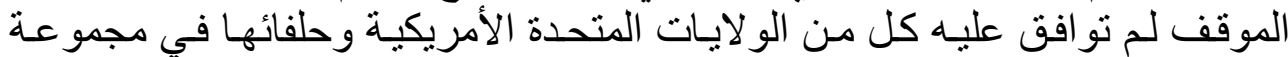

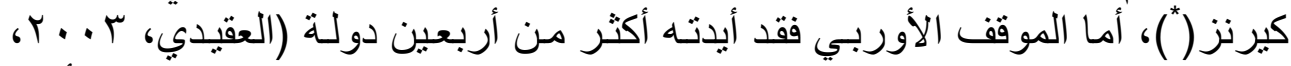

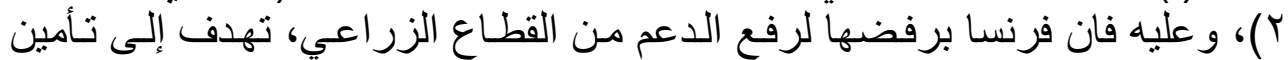

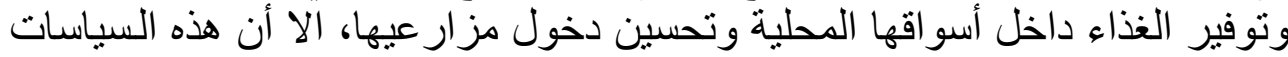

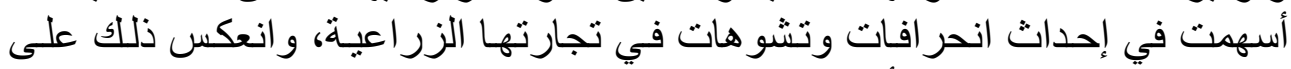

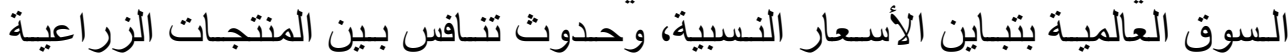

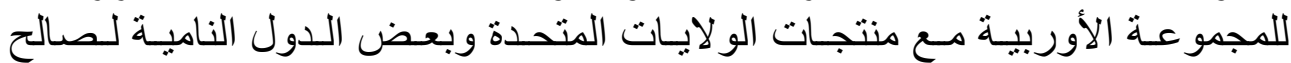

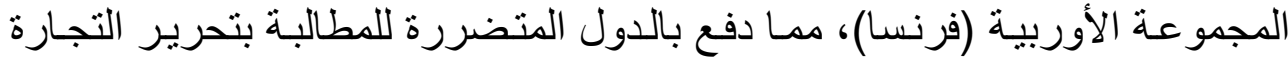

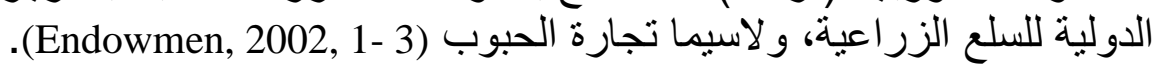

(") ارجنتين، استر اليا، بوليفيا، كندا، البرازيل، تشيلي، كولومبيـا، كوستاريكا، فيجي، كو اتيمـالا، اندونيسيا، ماليزيا، نيوزيلاند. 
وكانت الدول النامية في مقدمة الدول المطالبة بتنفيذ اتفاقيات الزر اعة في جولة

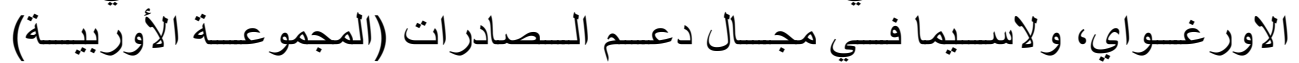

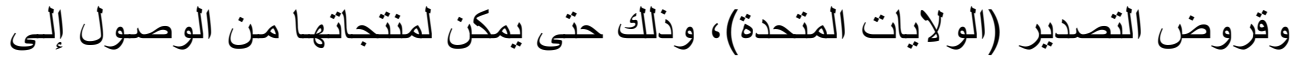

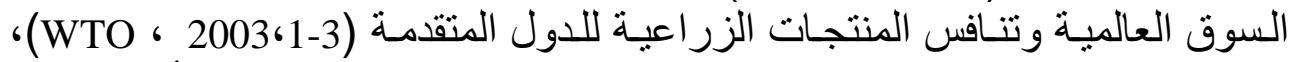

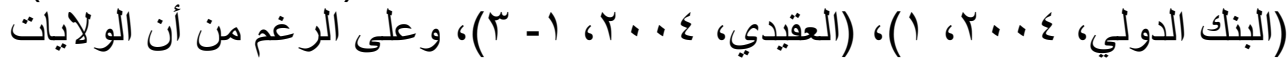

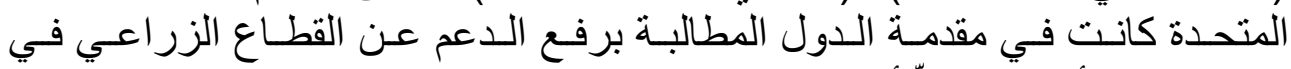

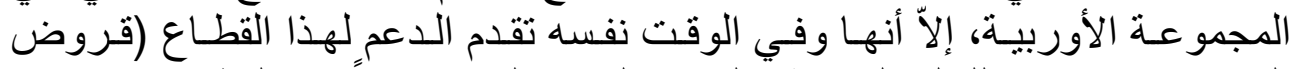

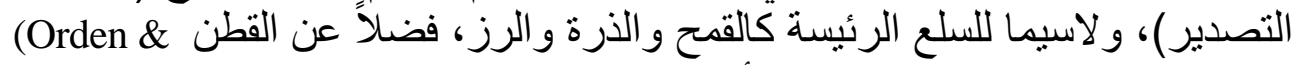

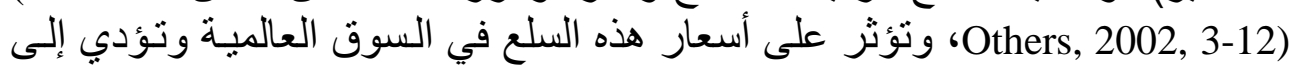

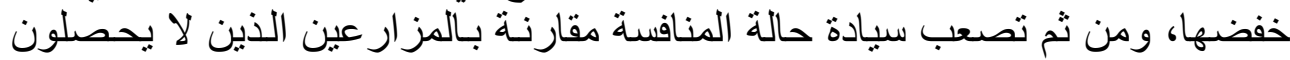

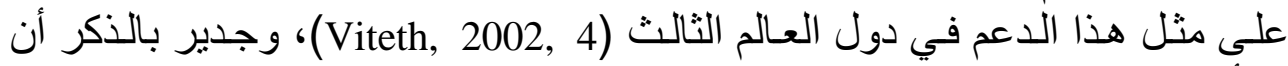

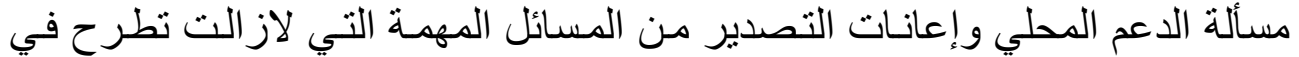

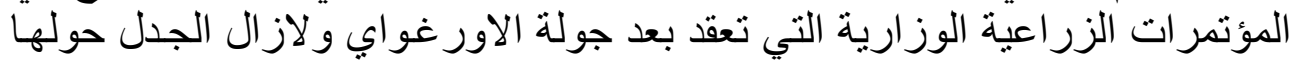

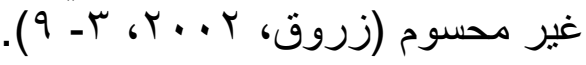

r. أثر تحرير التجارة على أسواق الحبوب (القمح أنموذجا)

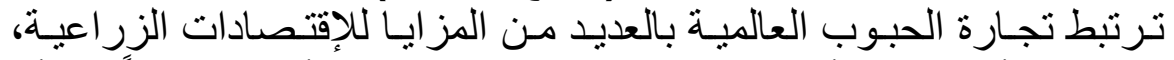

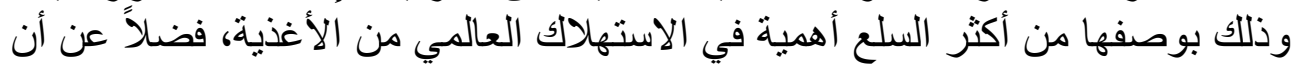

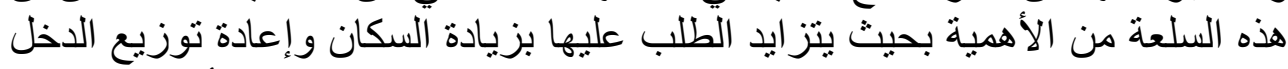

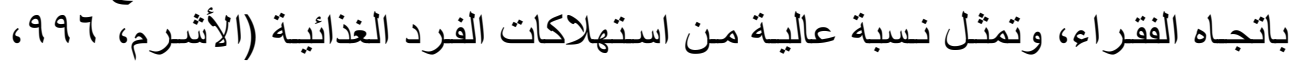

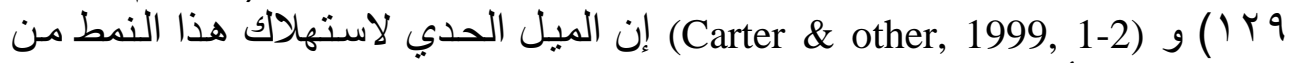

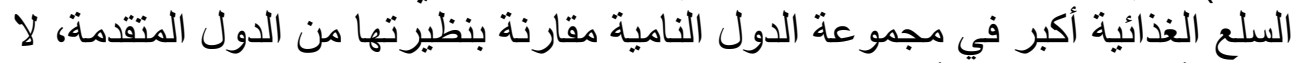

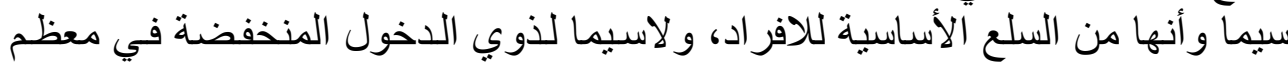

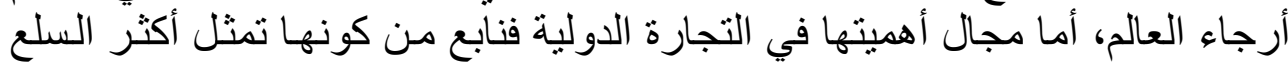

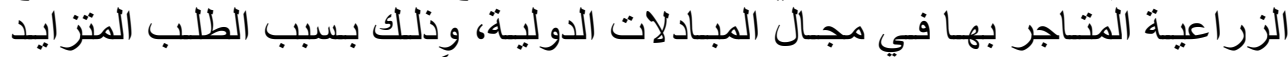

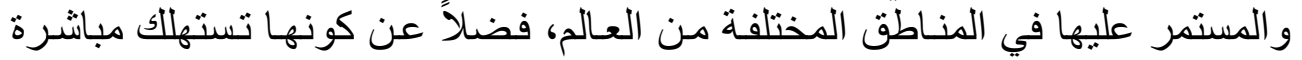

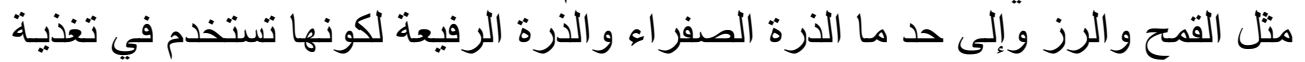

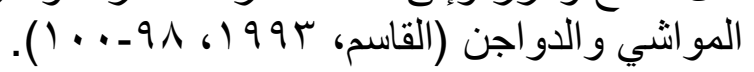

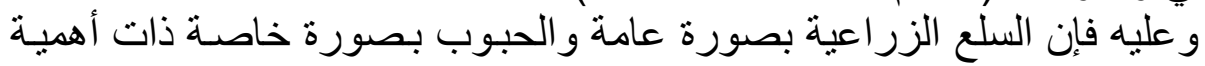

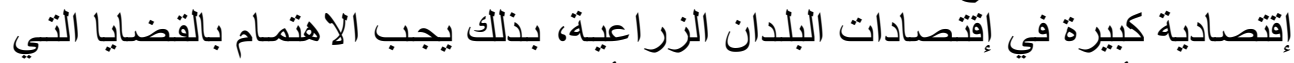

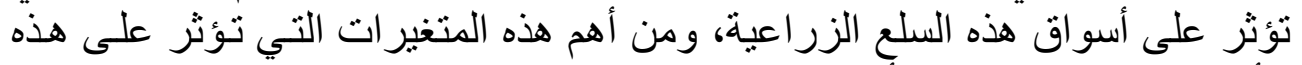

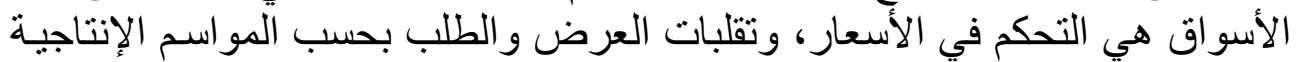

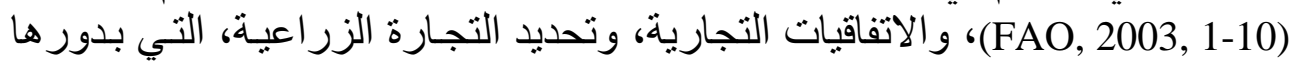

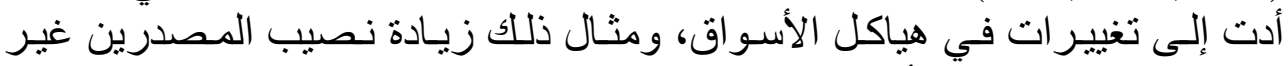

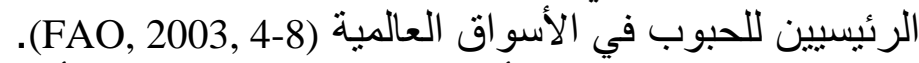

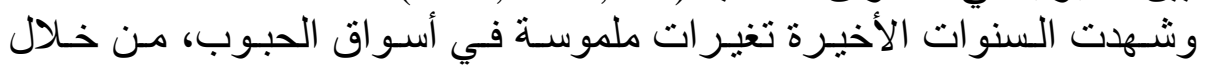

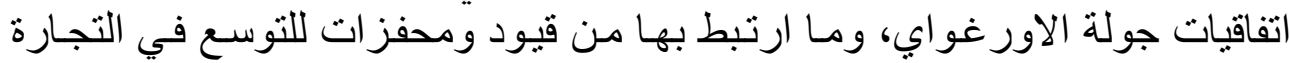




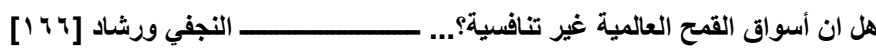

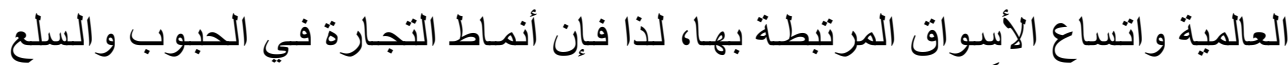

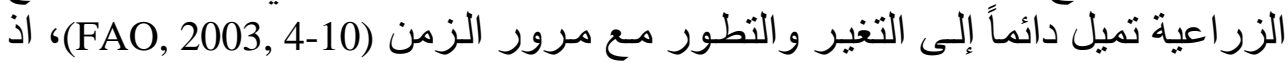

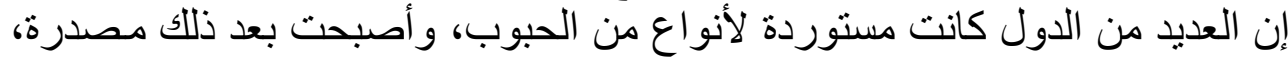

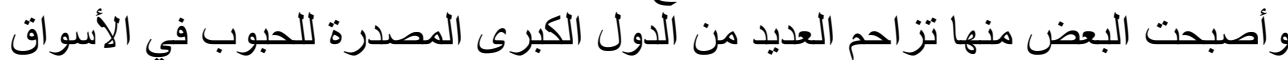

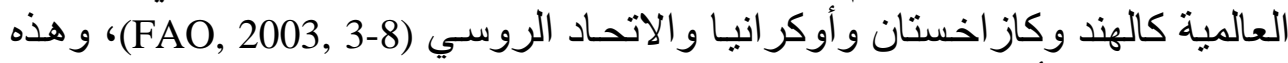

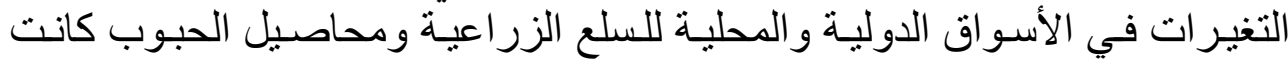

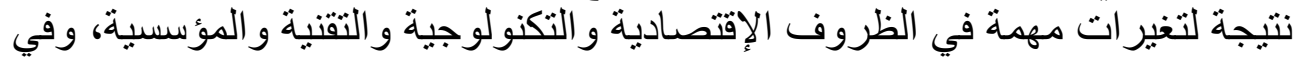

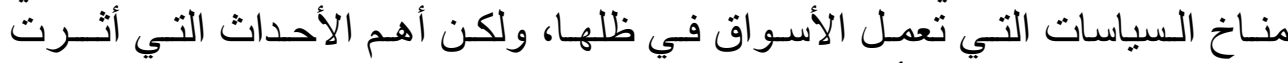

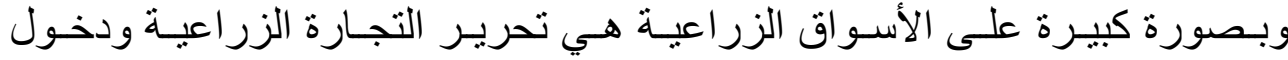

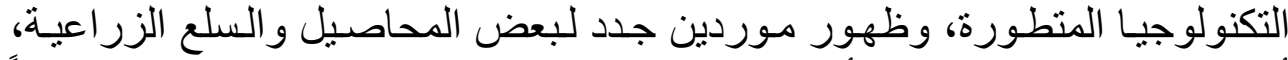

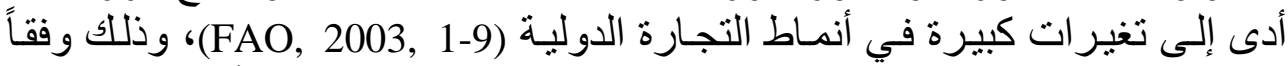

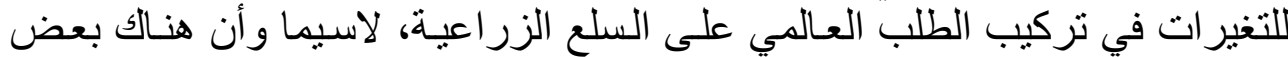

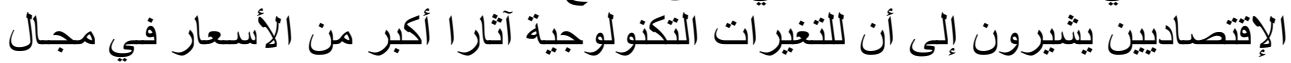

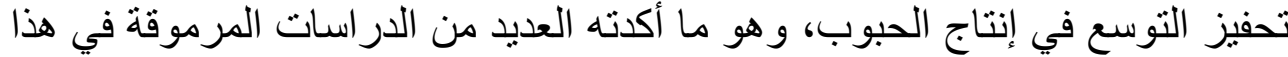

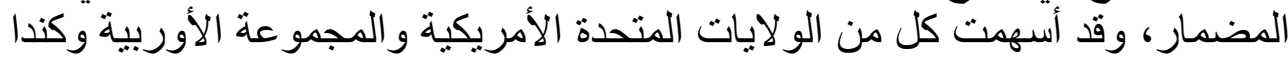

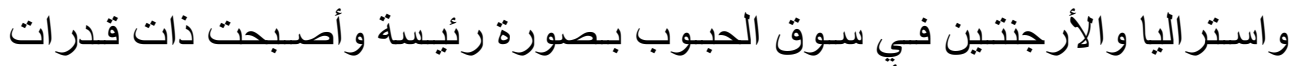

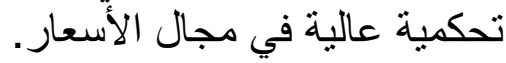

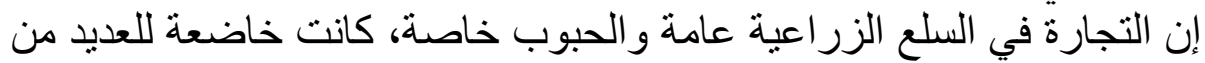

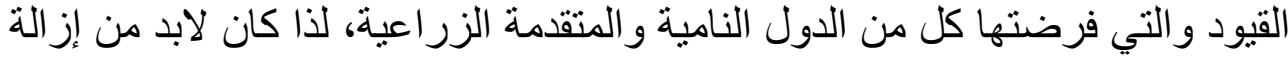

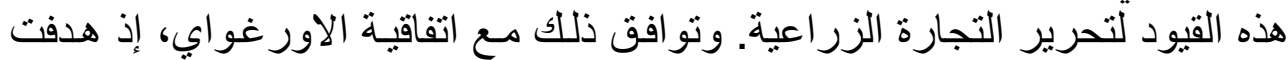

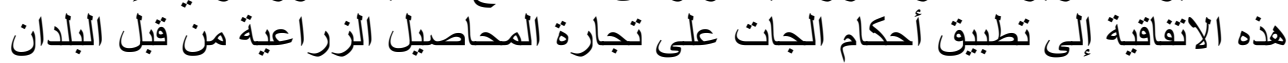

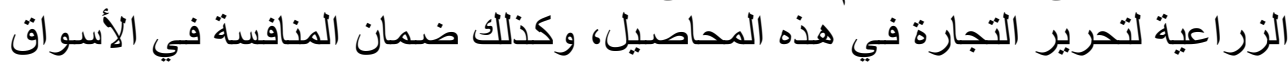

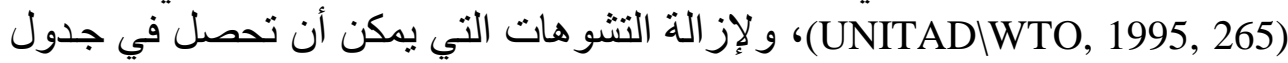

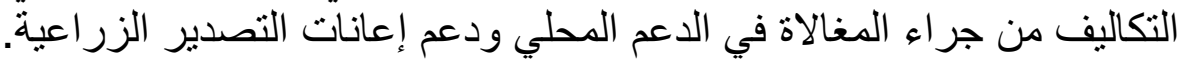

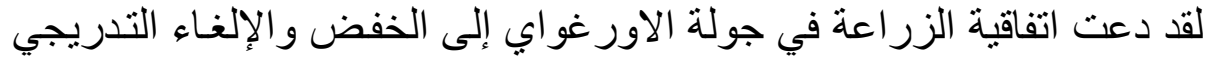

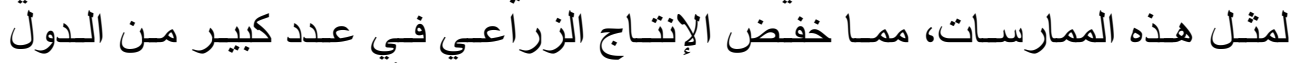

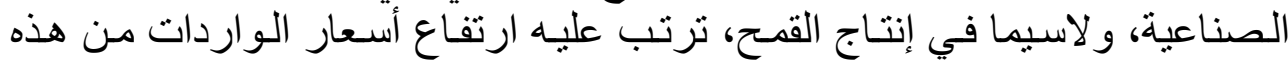

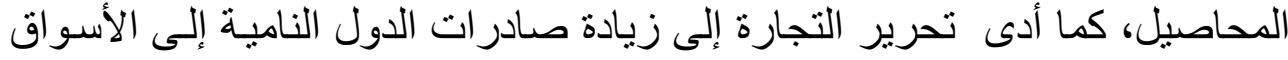

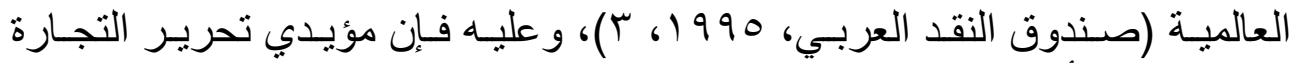

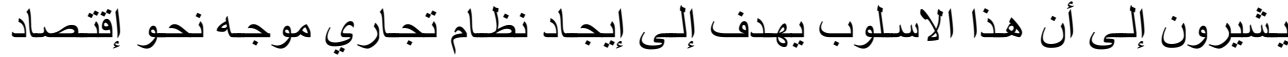

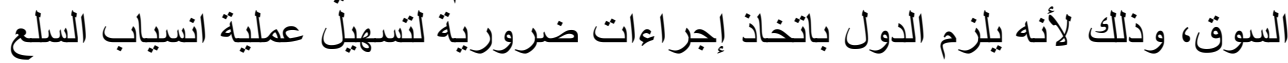

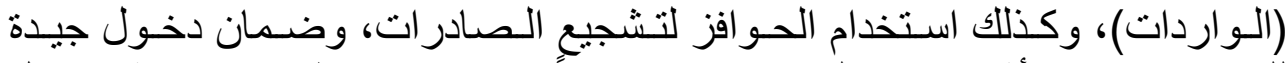

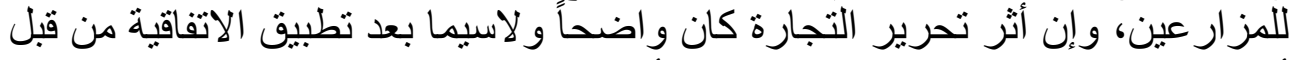

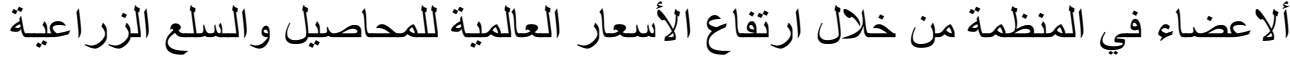

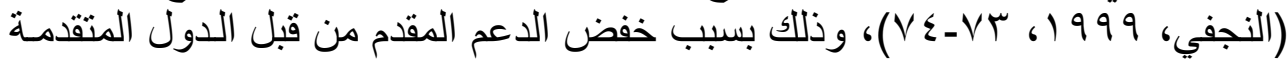

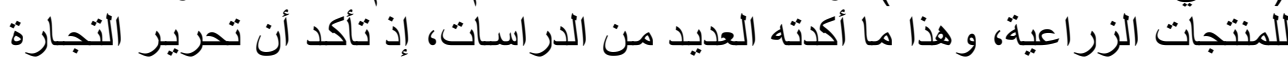

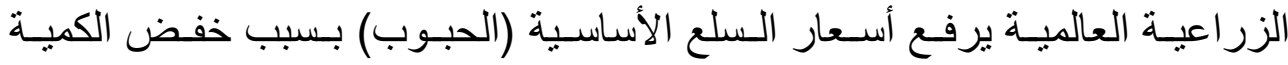


المعروضة منها في السوق العالمية من قبل الدول المتقدمة (المنظمة العربيـة للتنمية

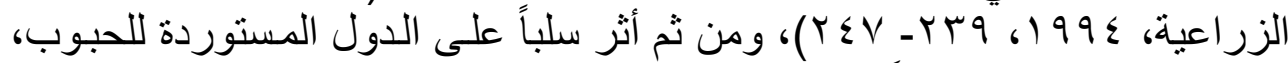

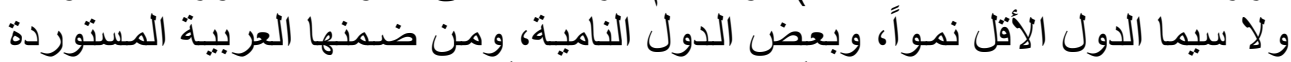

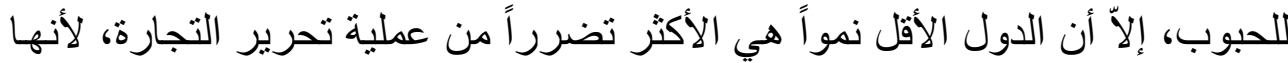

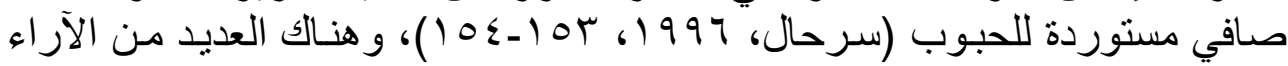

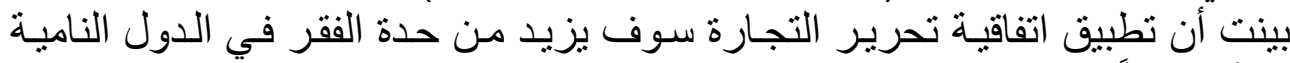

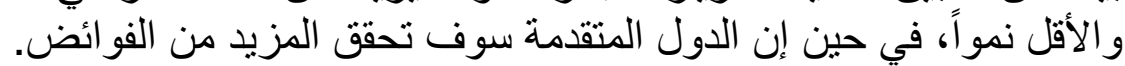

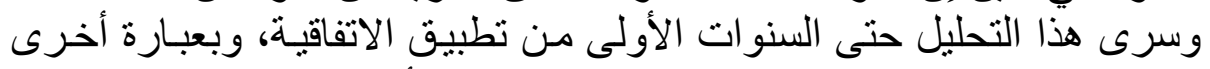

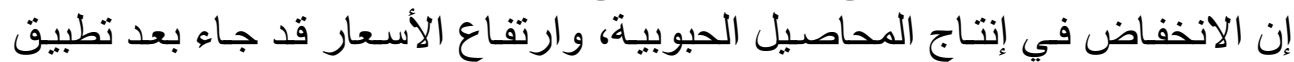

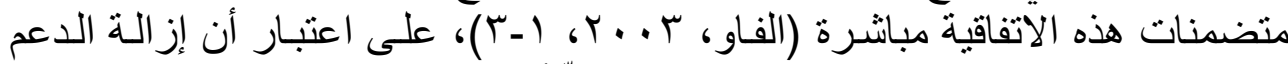

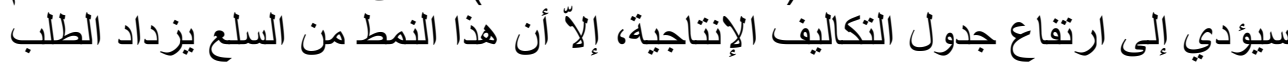

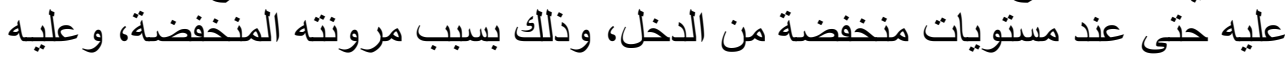

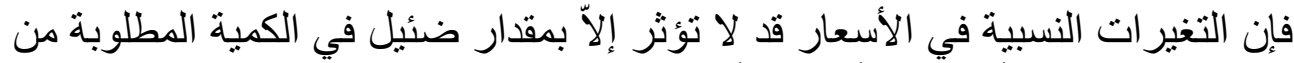

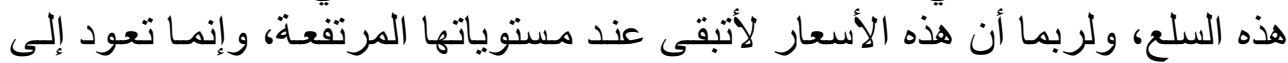

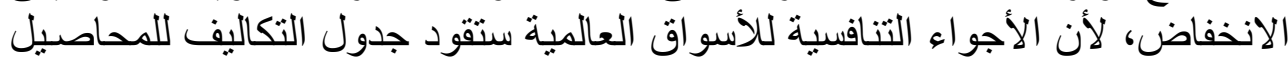

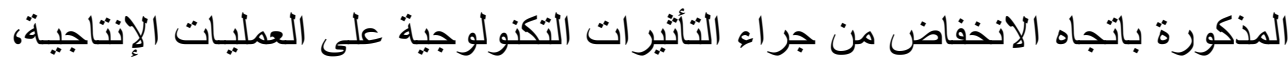

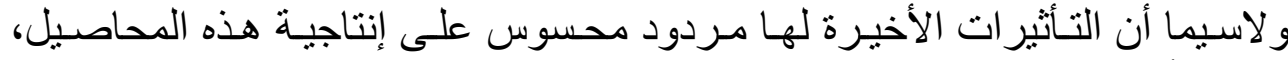

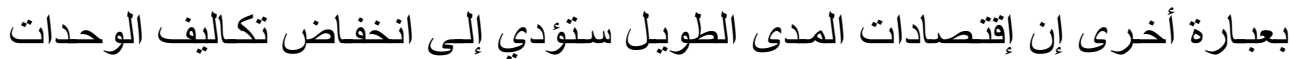

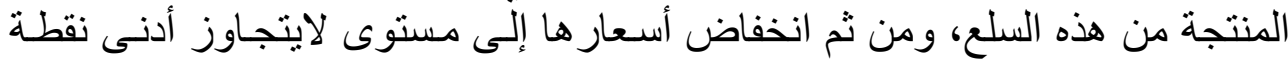

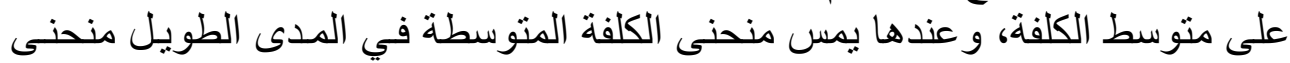

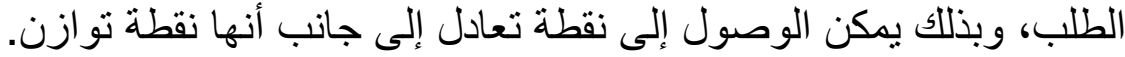

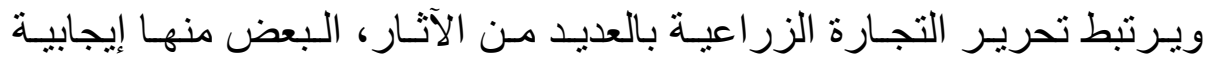

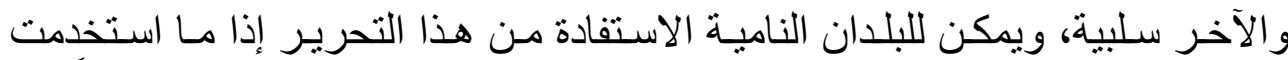

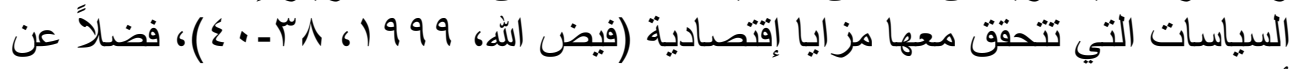

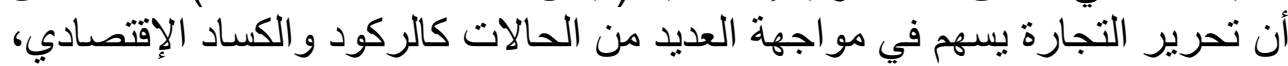

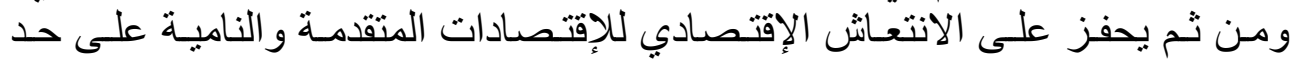

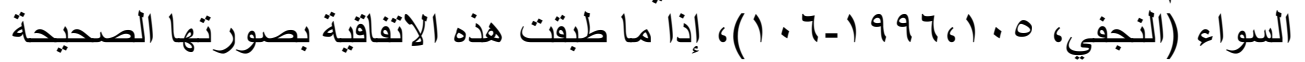

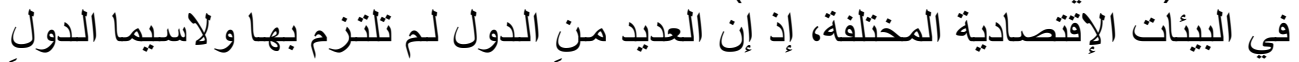

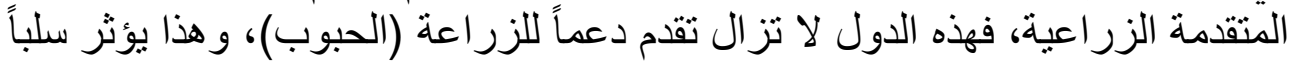

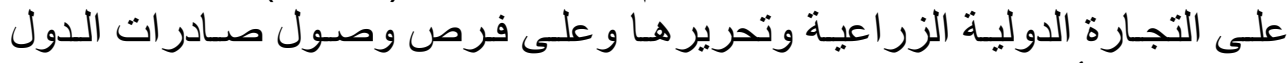

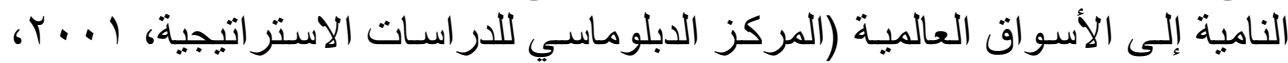

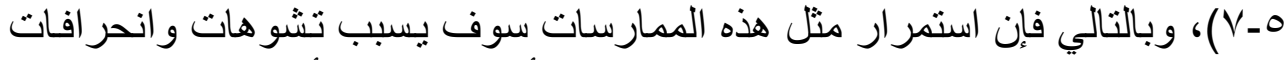

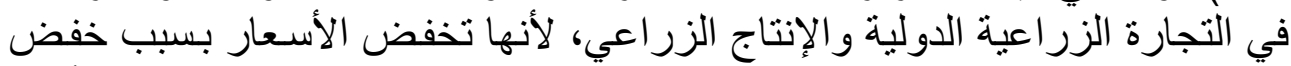

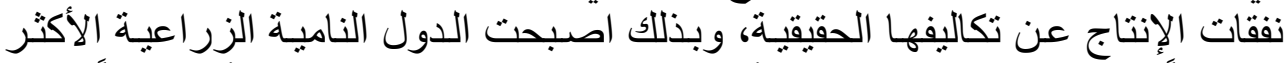

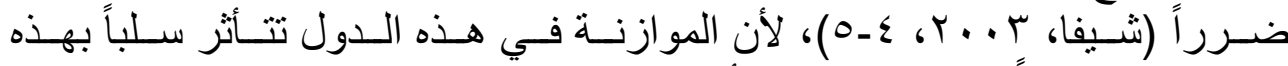

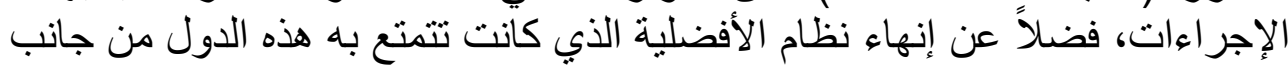

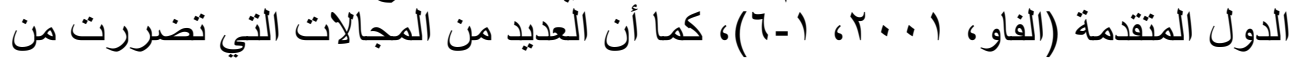




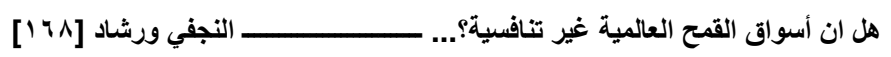

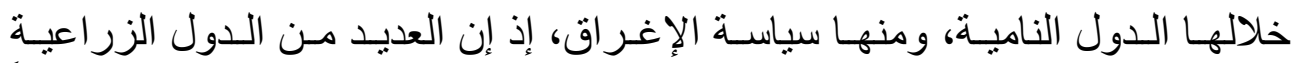

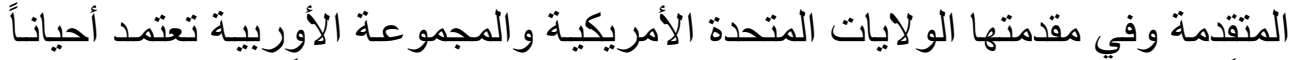

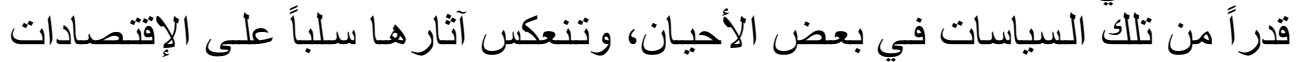
الزر اعية النامية.

إن المنتفعين الأساسيين من هذه الإجر اءات هي الشركات الزر اعيـة المتعددة

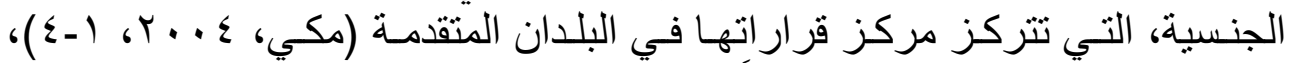
و عليه فإن الأسعار المنخفضة أحياناً في السوق العالمية بسبب الإغراق، سوف تؤدي أني

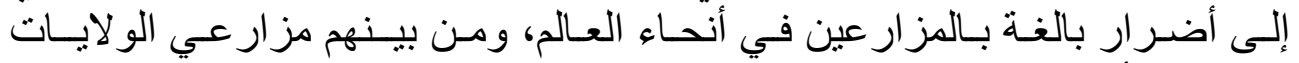

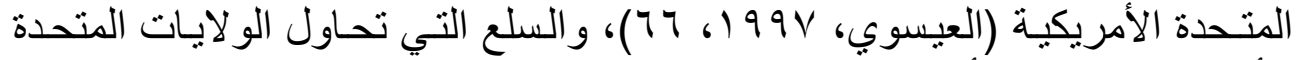

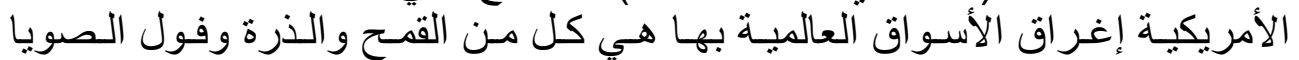

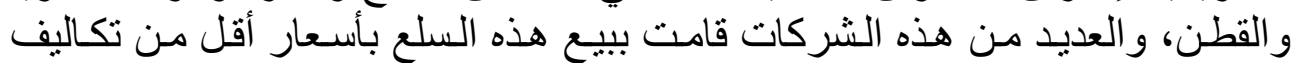

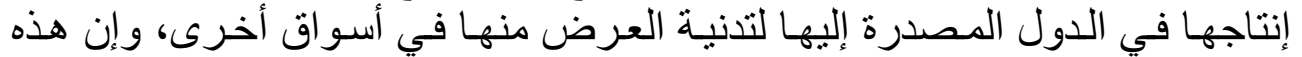

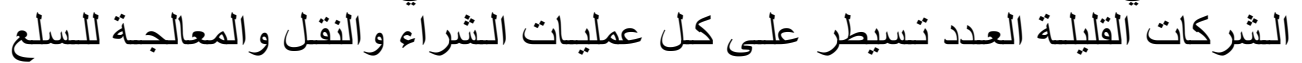

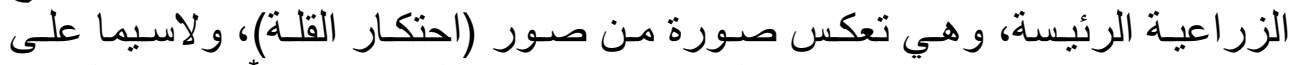

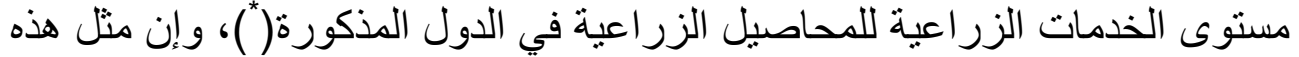

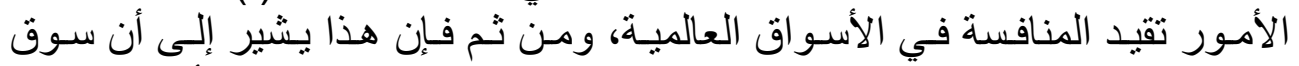

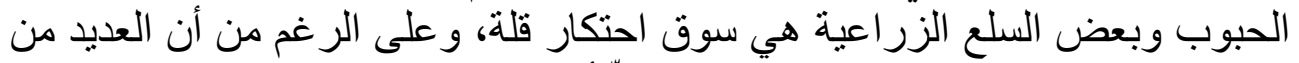

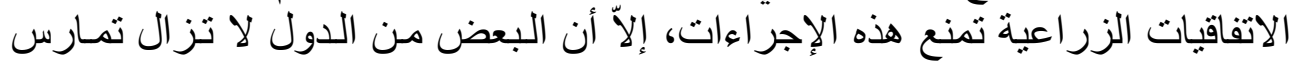
هذه السياسة على نطاق و اسع.

ب-1 إيكل سوق القمح

يعد القمح من السلع الغذائية الأساسية والإستر اتيجية وهو يحتل أهمية كبيرة في

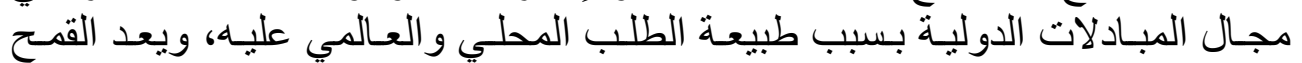

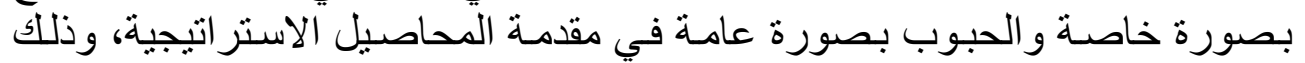

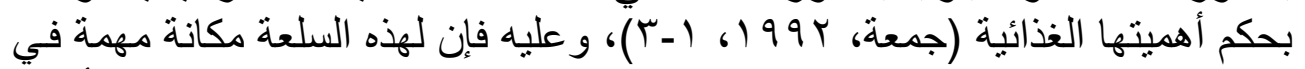

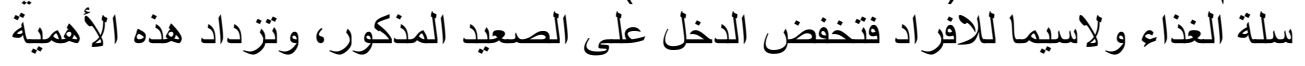

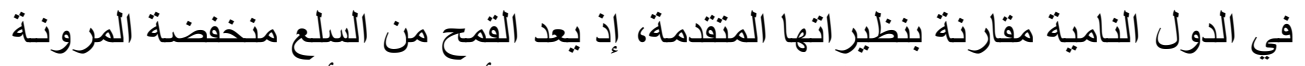

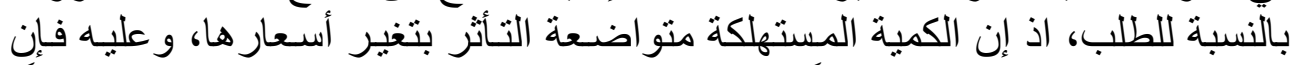

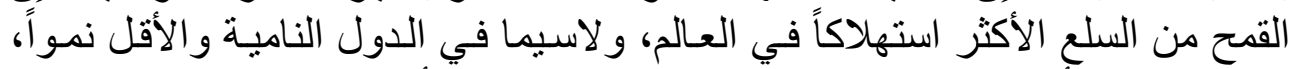

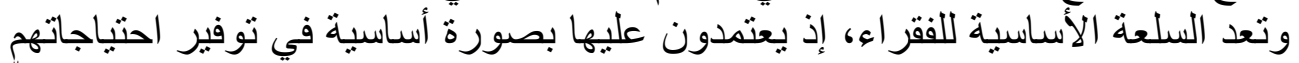

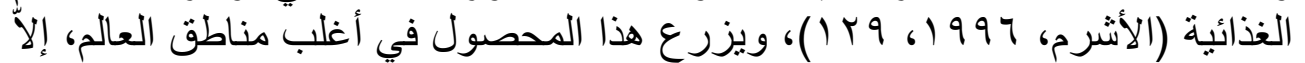

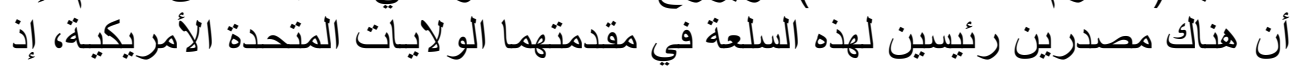

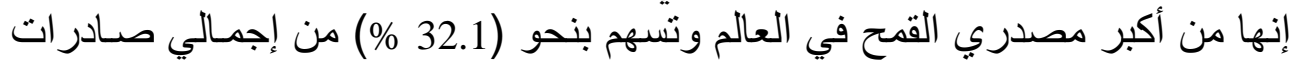

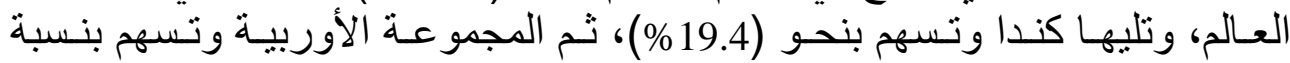

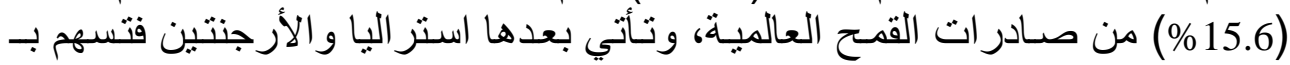




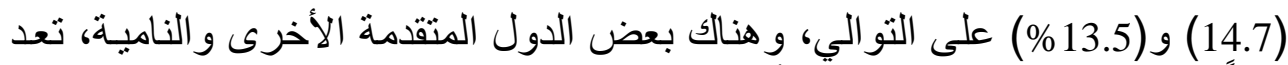

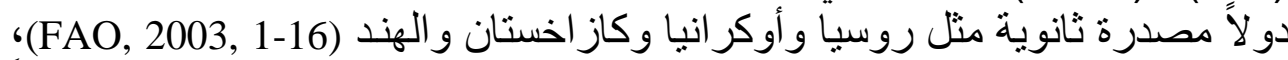

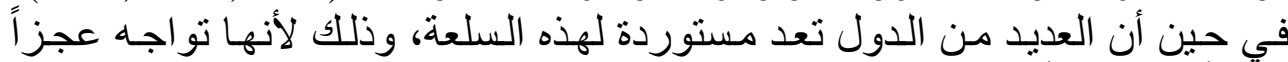

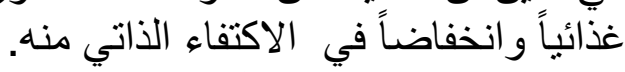

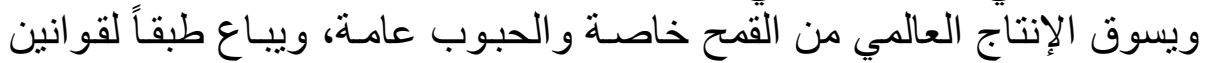

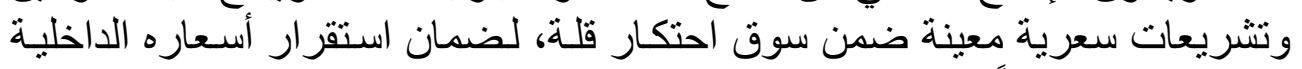

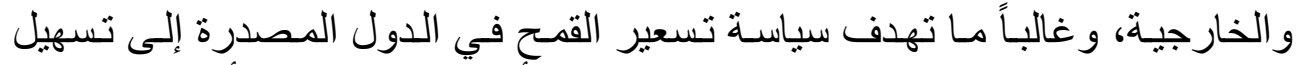

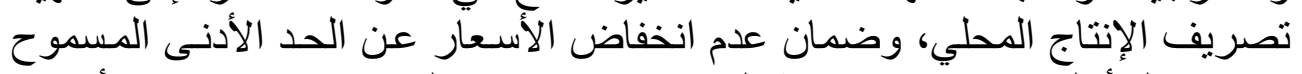

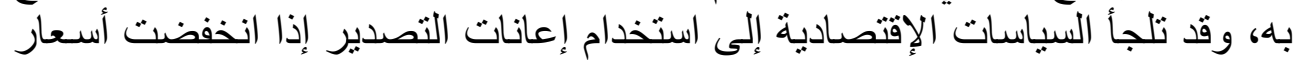

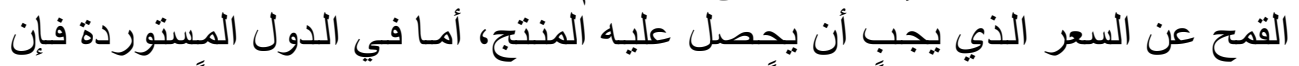

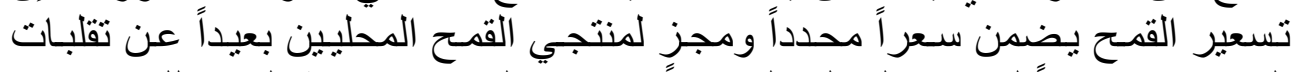

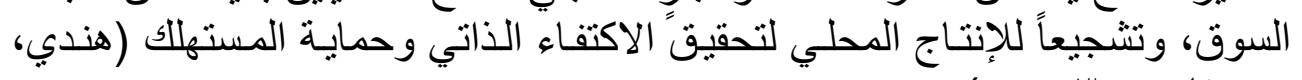

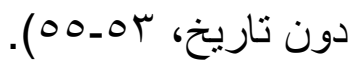

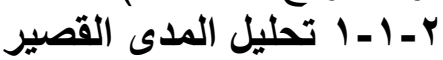

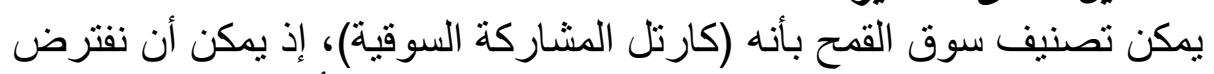

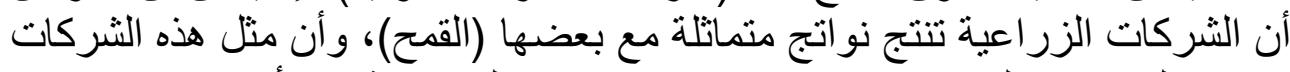

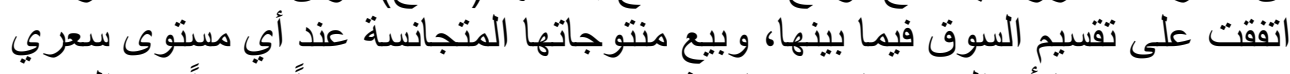

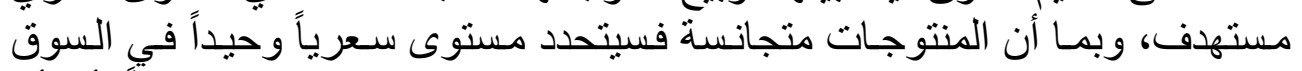

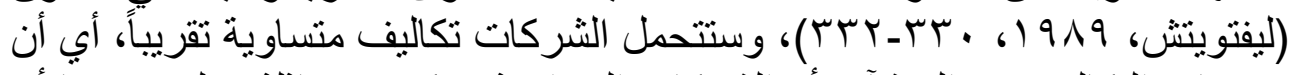

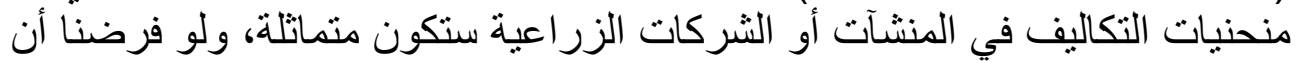

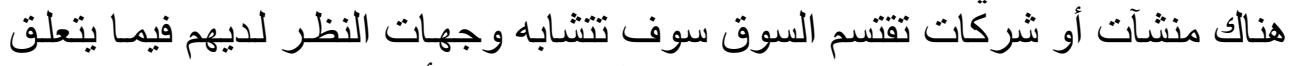

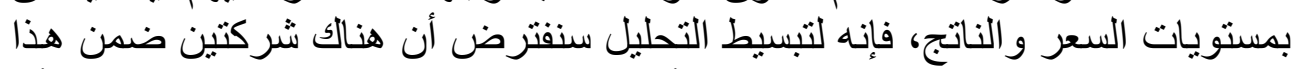

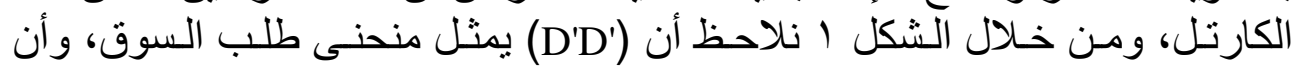

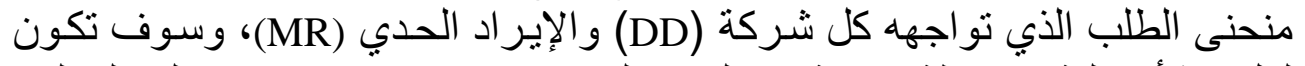

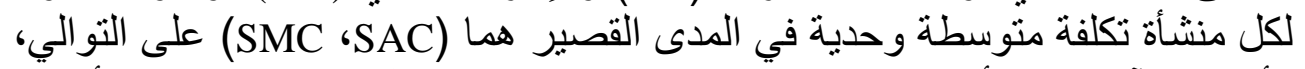

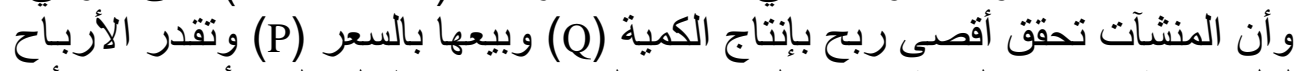

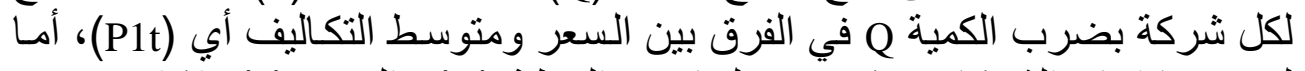

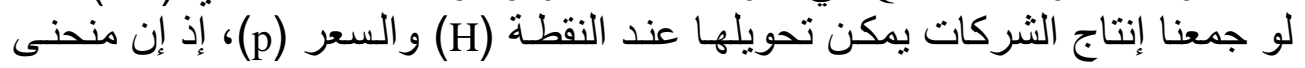
الطلب (DD)، يقع في منتصف المسافة بين منحنى الطلب السوقي (D'D')، ومحور الأسعار. - ماب.

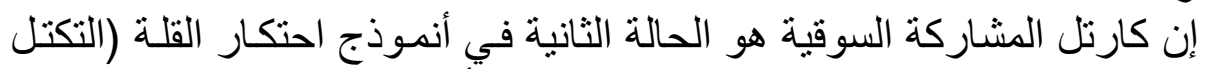

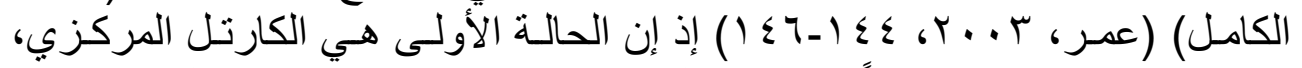

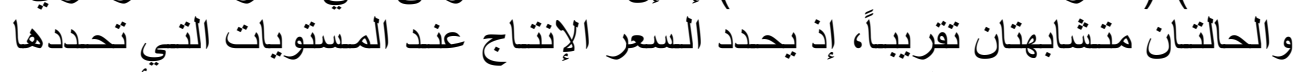

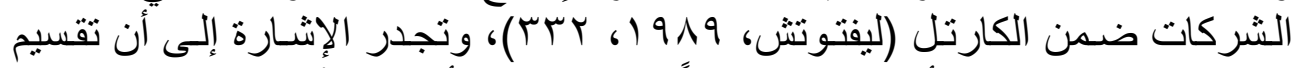

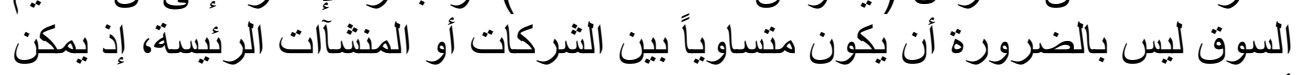

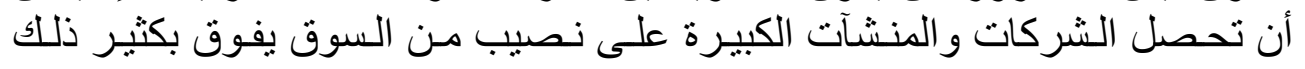




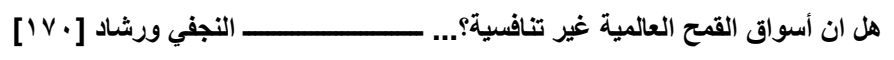

(Koustoyianis, 1988, 243- الجزء الذي تحصل عليه الشركات و المنشآت الأصـغر

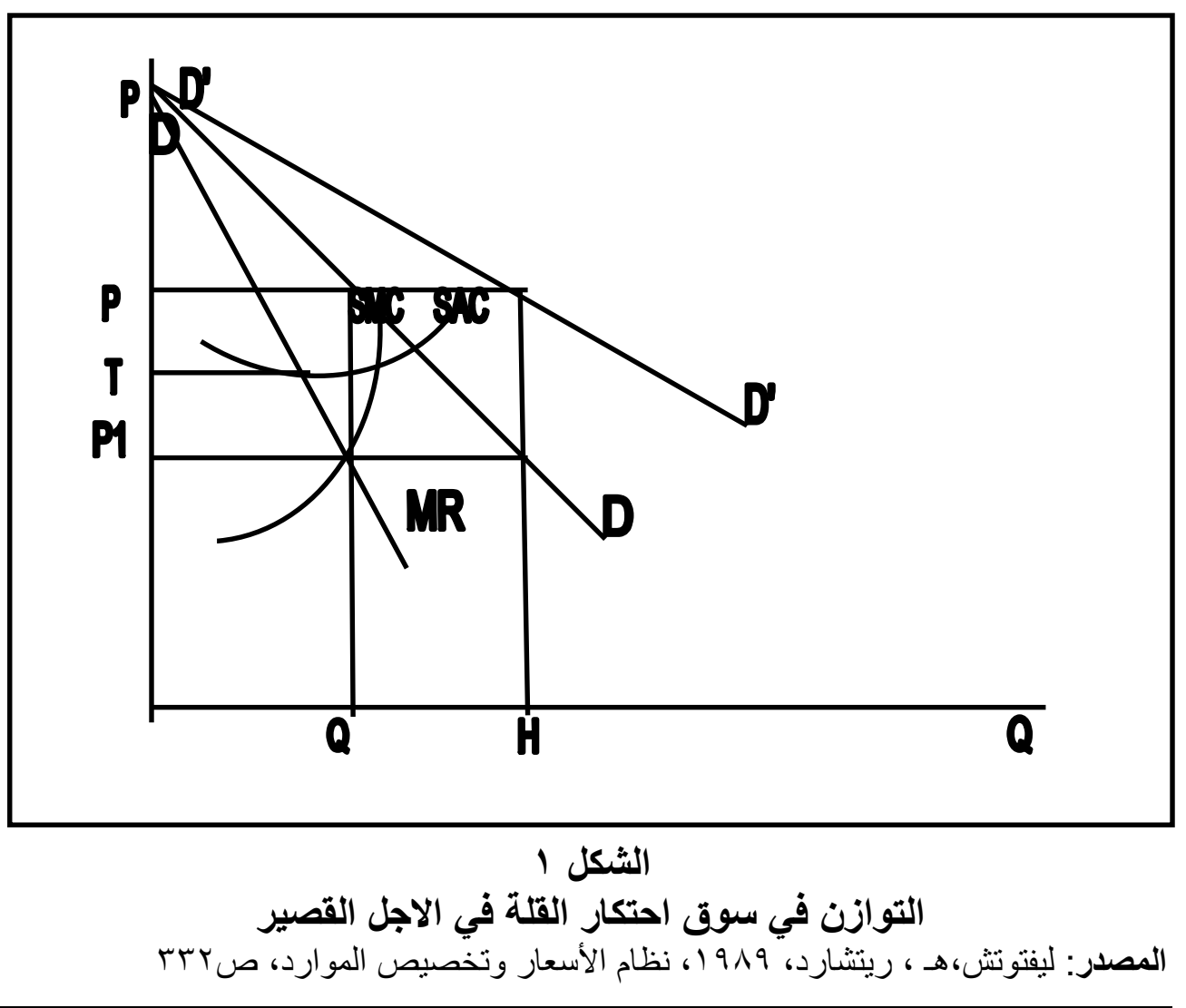

Y - ا ـ ب تحليل المدى الطويل تستطيع شركات إنتاج القمح في حالة احتكار القلة في المدى الطويل الطيل أن توسـع

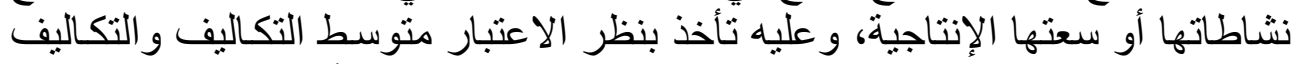

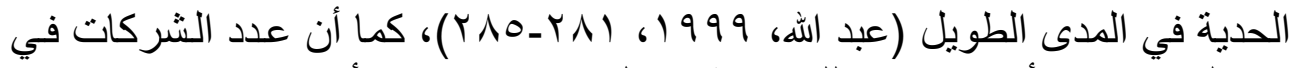

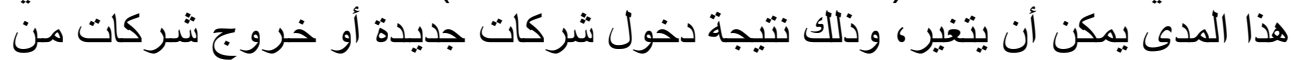

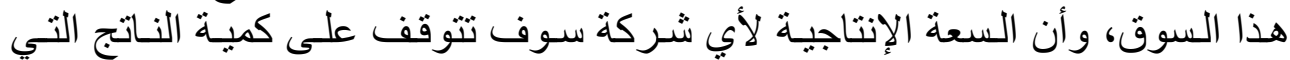

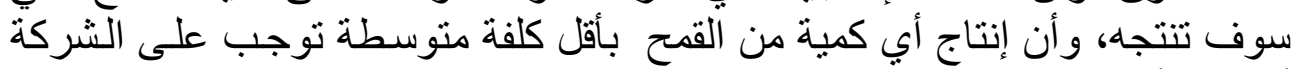

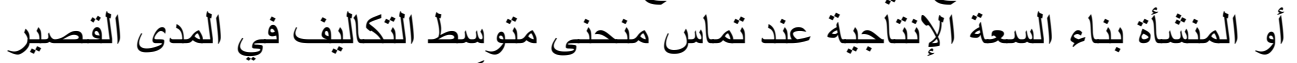

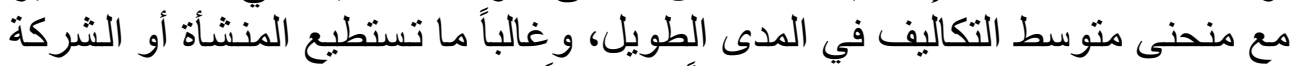

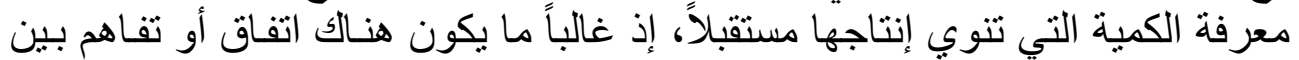




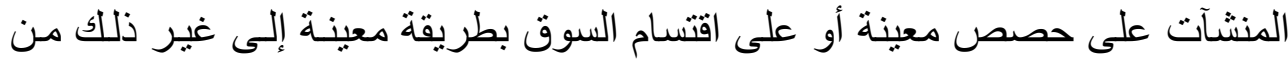

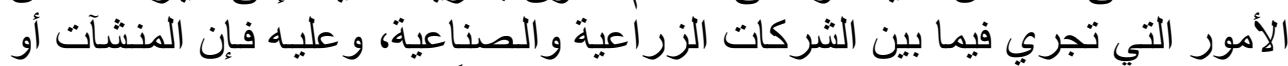

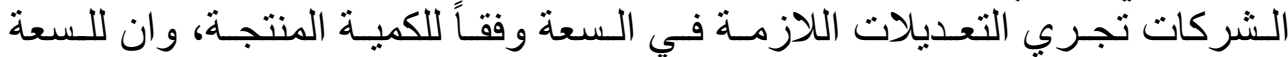

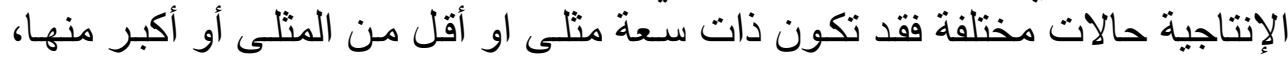

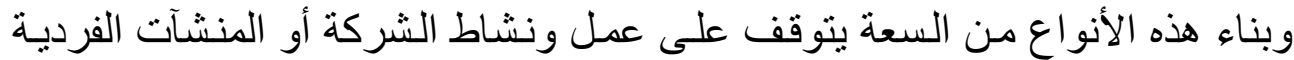

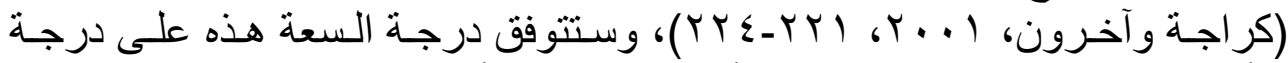

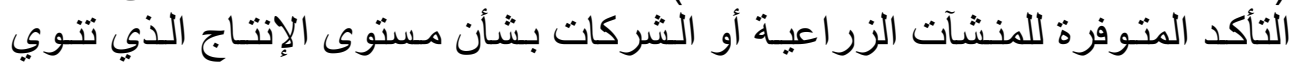
الثركة إنتاجه في المدى الطويل.

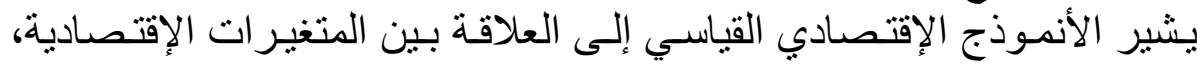

\section{r. توصيف الأنموذج}

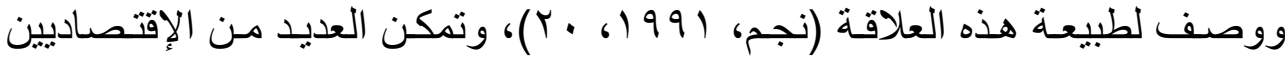

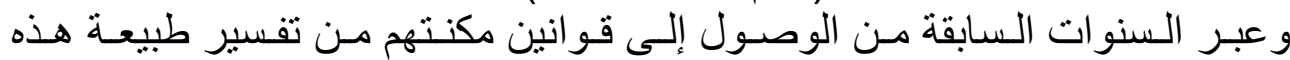

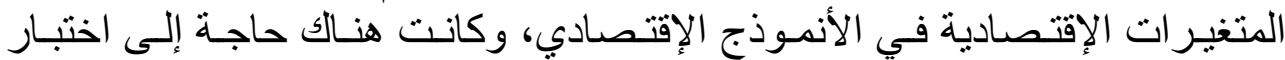

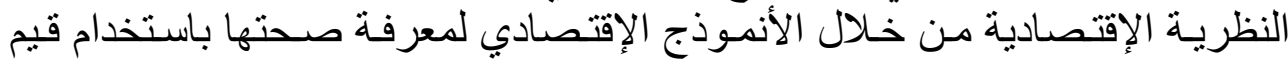

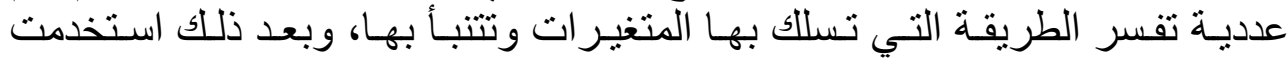

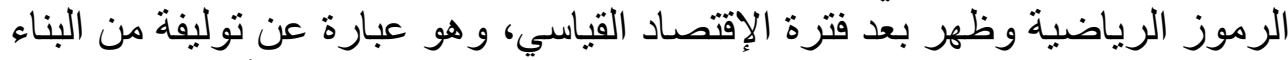

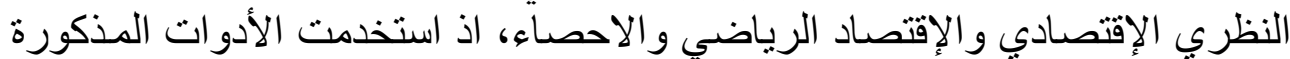

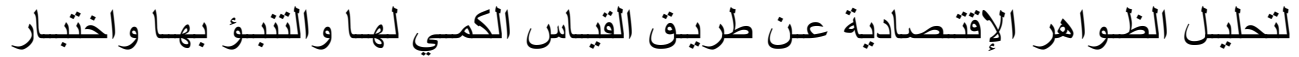

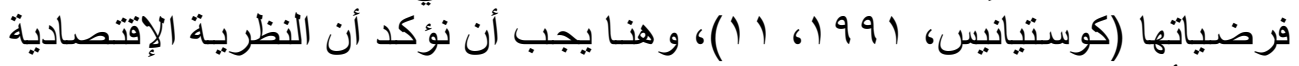
تمثل الأساس في بناء النماذج القياسية وهذه النماذج بدور ها تهدف ونان إلى اختبار صحة

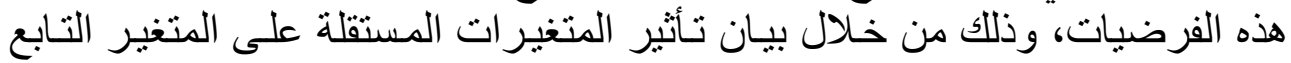

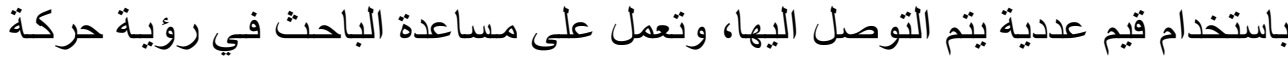

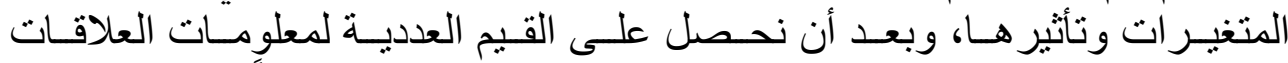

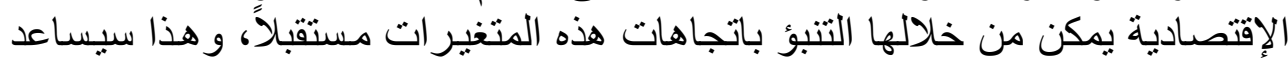

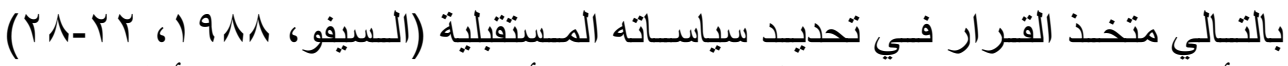

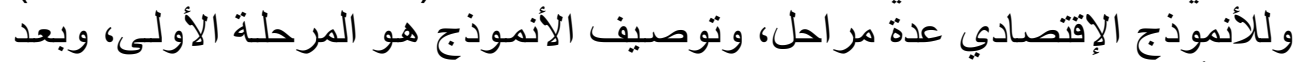

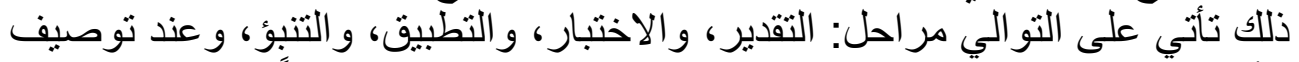

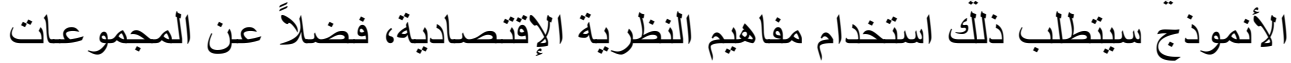

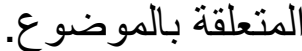

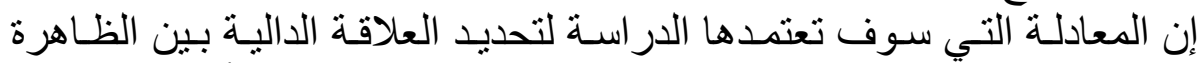

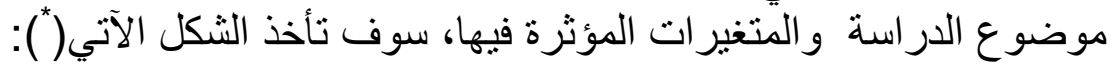
$Y=X+B_{1} X_{1}+B_{2} X_{2}+B_{3} X_{3}+\ldots \ldots . .+B x X x+U$

= المتغير المعتمد (صادرات القمح و الحبوب الخشنة) X 


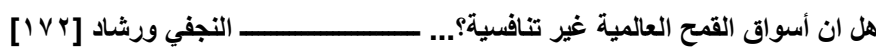

$$
\begin{array}{r}
\text { المتنغير ات }=X x \\
\text { المعلماتة }=B x \\
\text { المتغير العشوائي }=U
\end{array}
$$

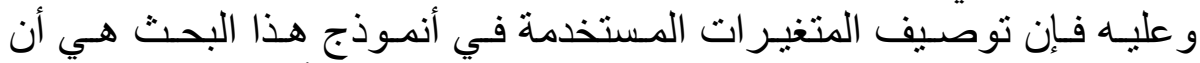

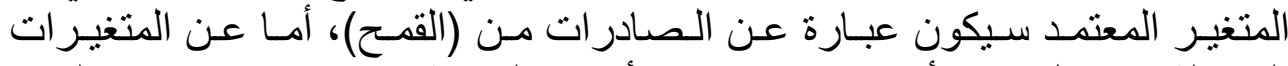

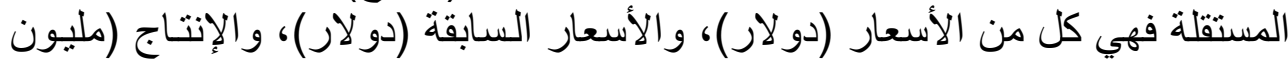

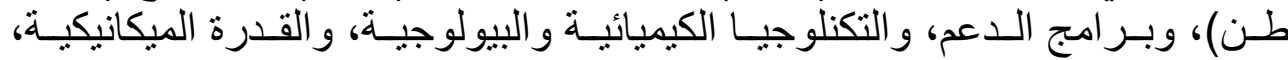

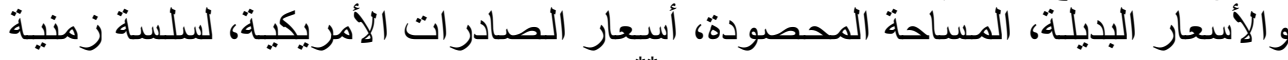

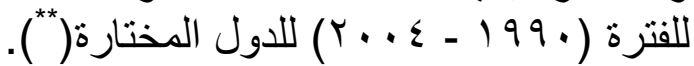

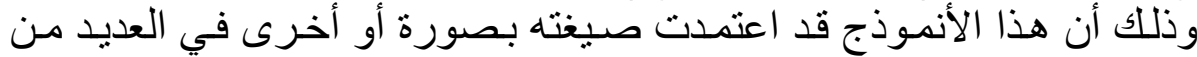

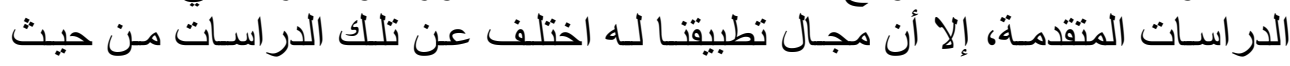

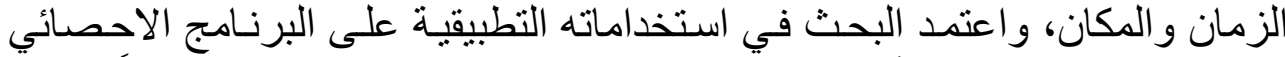
و الذي أمكن معه الحصول على قيم (Beta) التي تفسر وفقاً لمفهوم

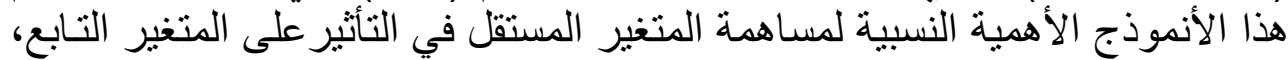

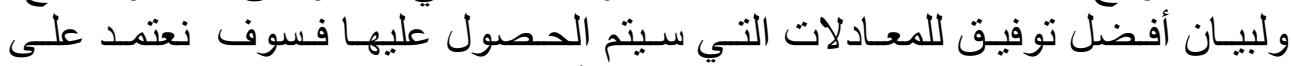

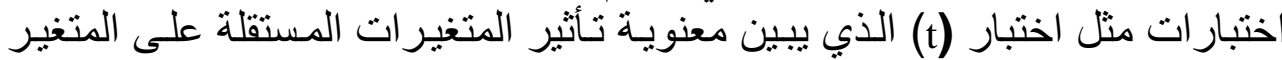

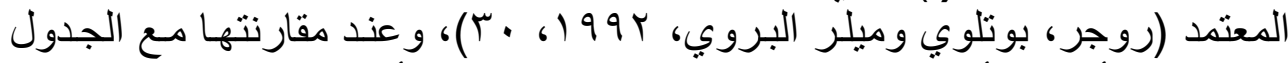

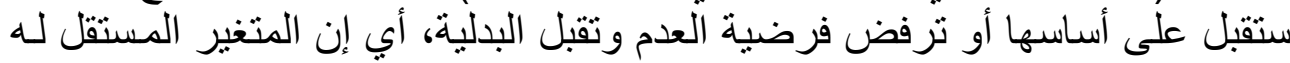

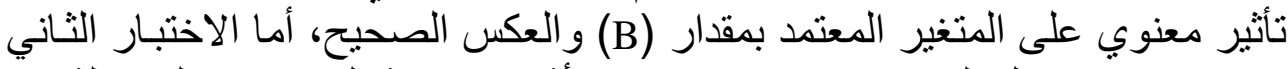

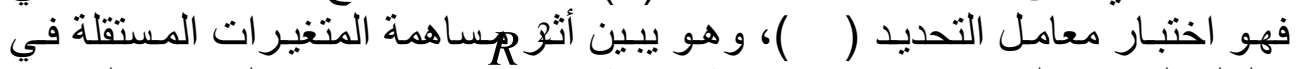

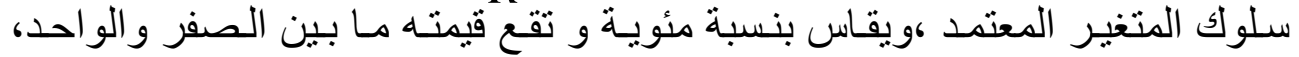

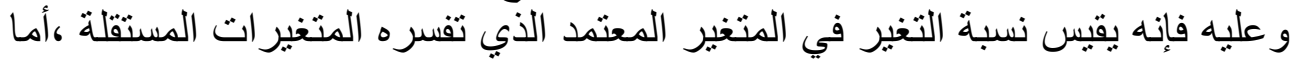

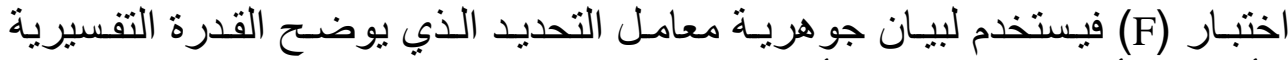

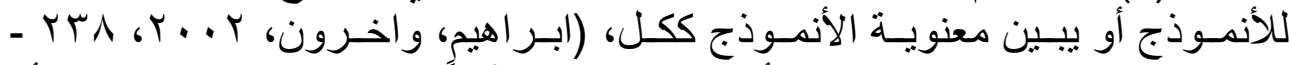

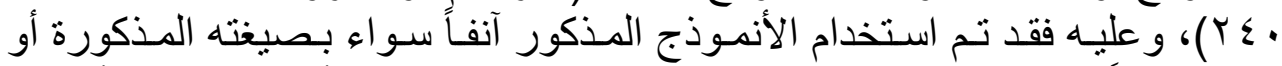

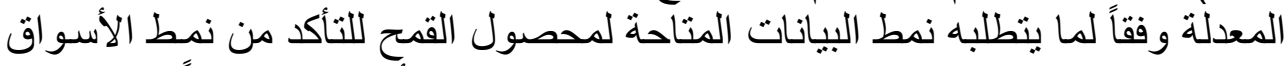

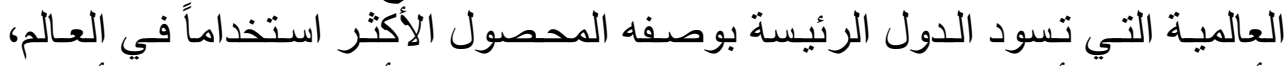

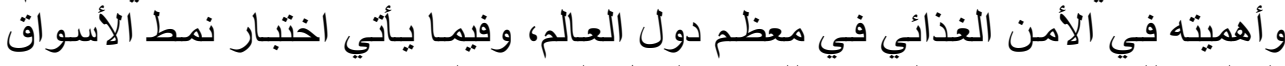

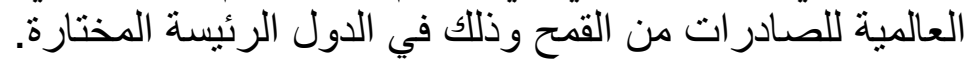

\section{ع. نماذج قياسية من أسواق القمح العالمية ـ - 1 الولايات المتحدة الأمريكية}

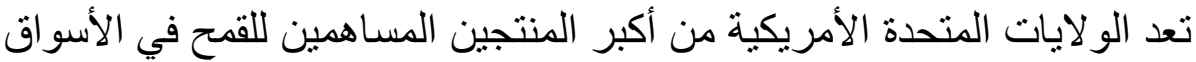

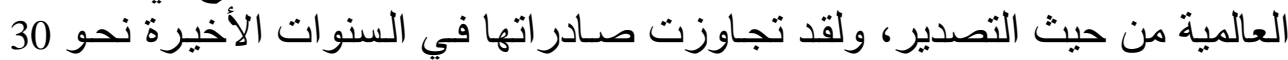

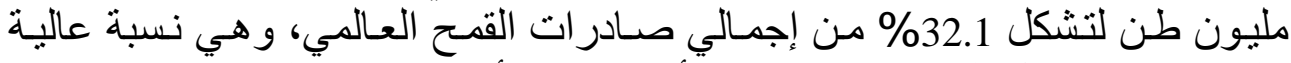

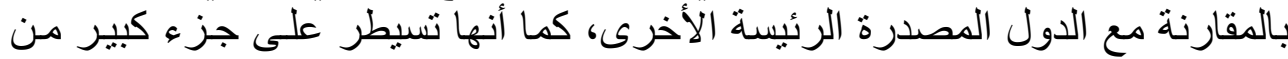




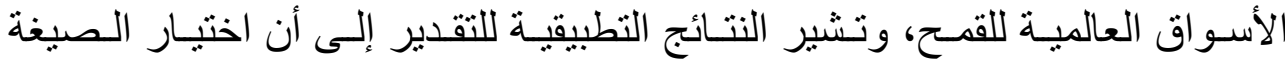

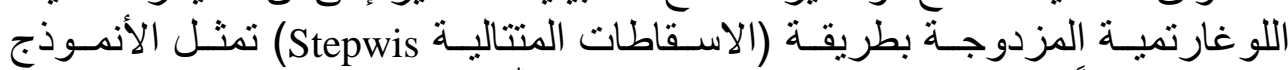
الأفضل تمثيلاً وقد أخذت الصنيخة الرياضية الآتية(").

$$
\begin{aligned}
& \log \mathrm{Y}=3.263+\begin{array}{l}
0.26 \log \mathrm{X}_{5} \\
\mathrm{~T}= \\
\left.R^{2}=44.235\right) \\
\mathrm{F}=10.47
\end{array} \quad, R^{-2}=40.34 \%
\end{aligned}
$$

$$
\begin{aligned}
& \text { الصادر ات الأمريكية من القمح (طن) = Y } \\
& \text { = الدم = X5 }
\end{aligned}
$$

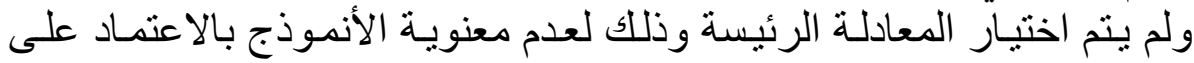

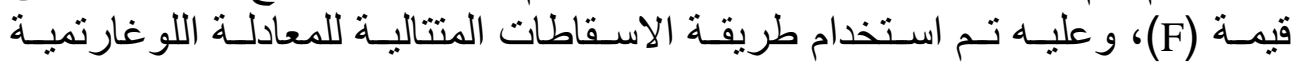

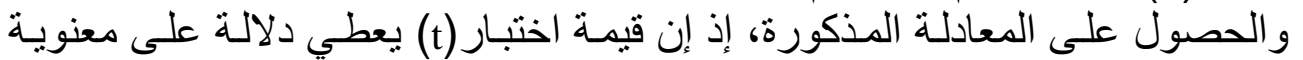

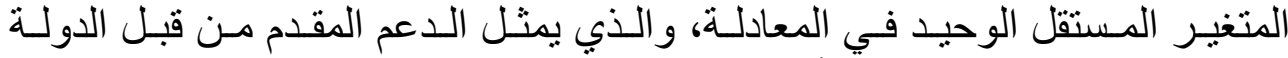
لصادر ات الحبوب، ونلاحظظ أن قيمـة معامـل التحديد (

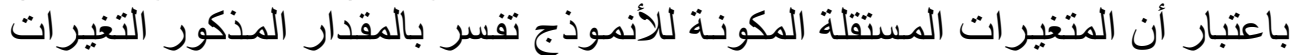

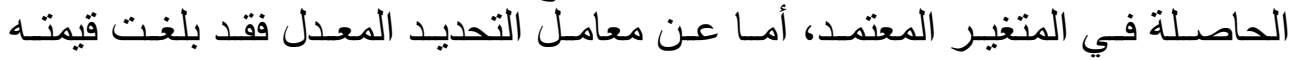
(40.34\%)، وعكست تأثثير المتغير ات المستقلة في المجتمع (السوق العالمية)، وفيما

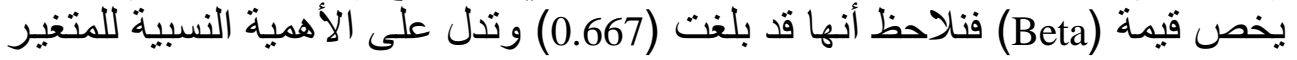

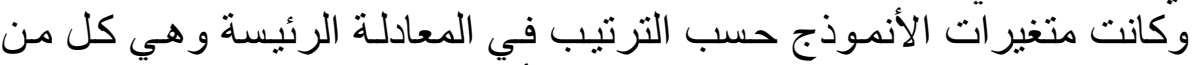
المعنوي الموجود في المعادلة.

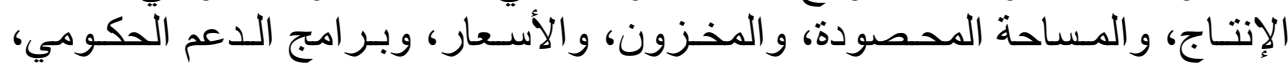

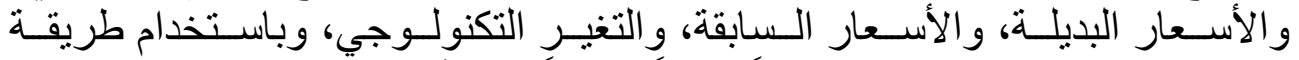

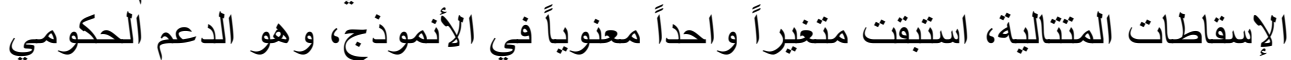

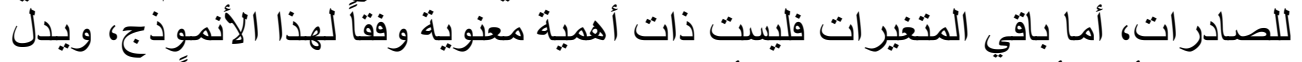

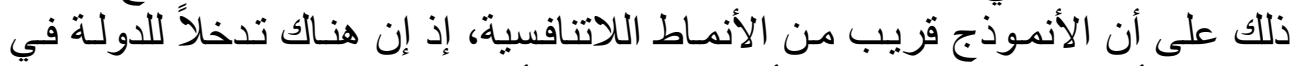

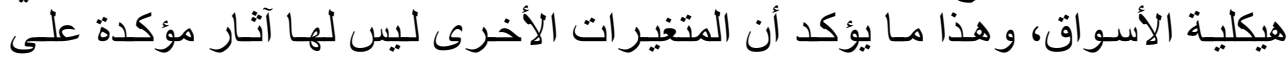

$$
\begin{aligned}
& \text { () الأنموذج الكامل لصادر ات القمح للو لايات المتحدة الامريكية . } \\
& \text { Logy }=-2.793-0.155 \log \mathrm{X}_{1}+0.66 \log \mathrm{X}_{2}+0.84 \log \mathrm{X}_{3}-0.78 \log \mathrm{X}_{4} \\
& \mathrm{~T}=\quad(-0.26) \quad(0.53) \quad(1.92) \quad(-1.16) \\
& +0.72 \log X_{5}+1.37 \log X_{6}-0.143 \log X_{7}+0.22 \log X_{8} \\
& \text { (2.60) (1.57) (-0.36) } \\
& R^{2}=\begin{array}{c}
40.76 \% \\
\mathrm{~F}=1.90
\end{array} \quad R^{-2}=34.11 \%
\end{aligned}
$$

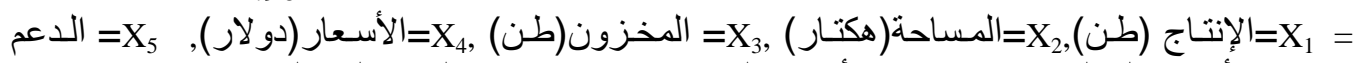

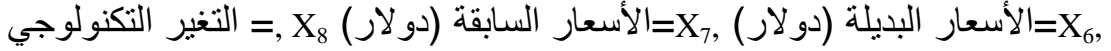




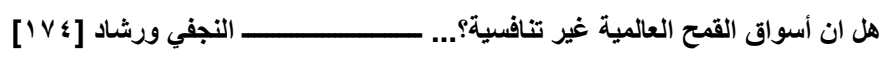

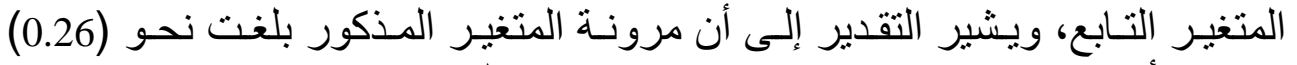

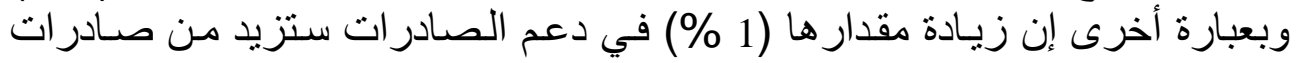
القمح بالمقدار المذكور.

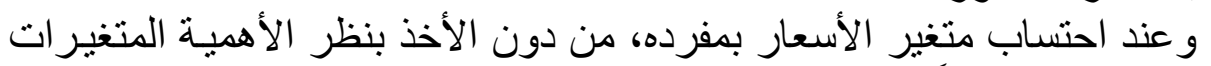

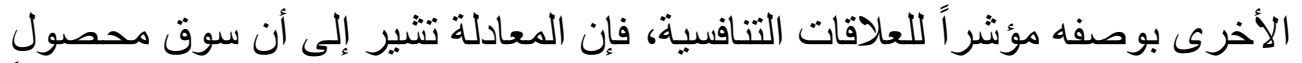

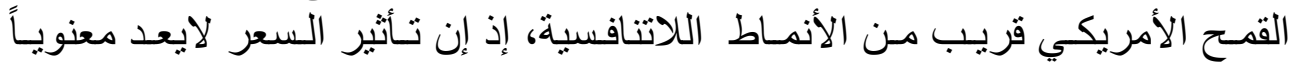
وبحسب المؤشرات الإحصائية كما في المعادلة الآتية: $\log Y=2.796+0.1089 \log X_{1}$

$$
\begin{aligned}
& \mathrm{T}= \\
& R^{2}=1.5 \% R^{-2}=1.0 \%
\end{aligned}
$$

S Y

تعد كندا من الدول الزراعية الرئيسة في إنتاج القمح، وتحتل المرتبة الثانية من

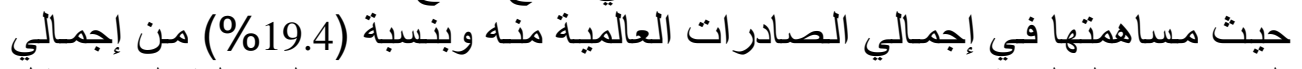

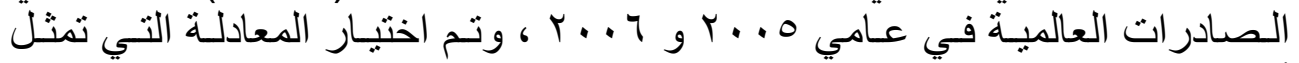

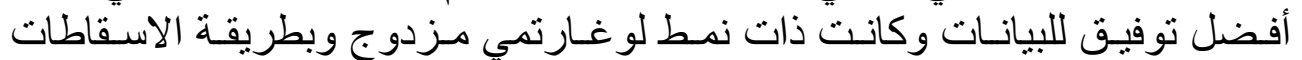

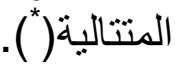

$$
\begin{aligned}
& \log \mathrm{Y}=3.217+0.4 \log \mathrm{X}_{1} \\
& \mathrm{~T}= \\
& R^{2}=53.80 \%, R^{-2}=46.10 \% \\
& \mathrm{~F}=6.98
\end{aligned}
$$

الصادر ات الكندية من القمح (طن) = Y X1

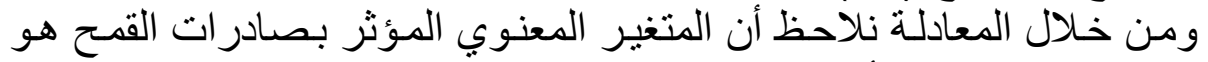

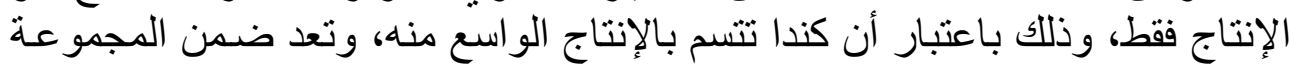

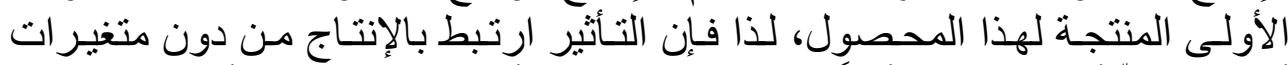

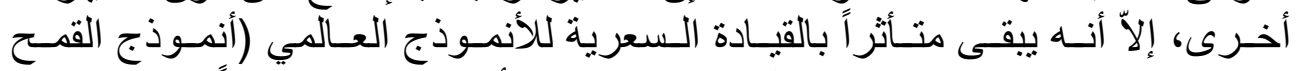

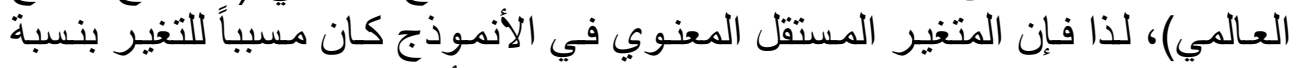
(53.80\%) من التغيرات الحاصلة في المتغير المعتمد، أما عن معامل التحديد المعدل المعل

( ) الأنموذج الكامل لصادر ات القمح الكندية $\log y=3.26+0.493 \log X_{1}-0.492 \log X_{2}+0.10 \log X_{3}-0.026 \log X_{4}$
(1.59)
$(-0.69)$
(0.09) (-0.06)

$-0.046 \log \mathrm{X}_{5}+0.031 \log \mathrm{X}_{6}-0.017 \log \mathrm{X}_{7}$

$\begin{array}{lll}(-0.08) & (0.09) \quad(-0.02)\end{array}$

$$
\begin{aligned}
& R^{2}=55.00 \% \quad R^{-2}=45.00 \% \quad \mathrm{~F}=0.86
\end{aligned}
$$

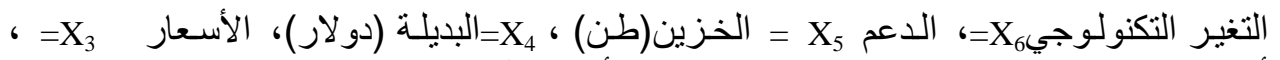

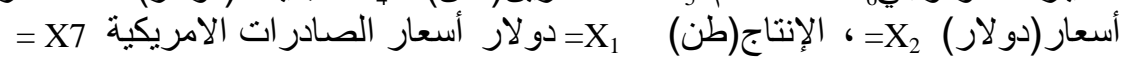


$(r \cdot)^{9} \cdot$

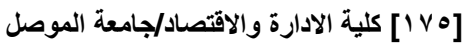

فقد بلغت قيمته (46.98 \%)، في حين بلغت قيمة (BETA) نحو (4.542) وتشير إلى الأهمية النسبية للمتغير المعنوي الوحيد في في المين المعادلة.

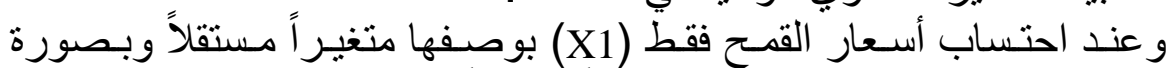

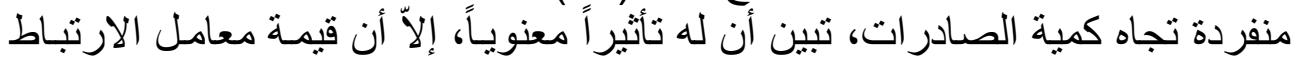

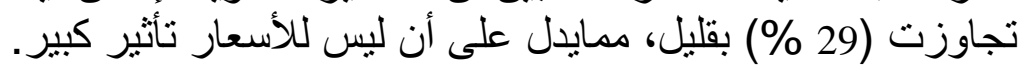
$\log \mathrm{Y}=5.640-0.584 \mathrm{X} 1$

$\mathrm{T}=$
$R^{2}=29.23 \%, R^{-2}=23.8 \%$

ع-ب المجموعة الاوربية

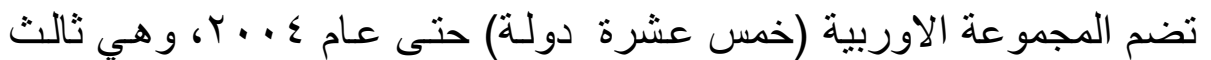

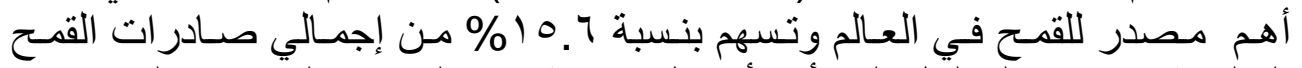

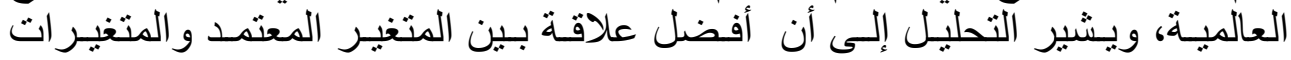

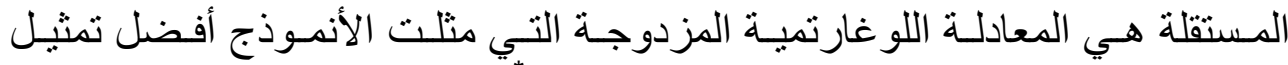
وباستخدام طرّيقة الاسقاطات المثالية (Stepwise)(").
$\mathrm{T}=$
(2.18)
$(-1.59)$
(3.4)
(2.00)
$(0.11)$
(2.01)

$\mathrm{R}^{2}=69.07 \%$

$\mathrm{R}-2=47.28 \%$

$\mathrm{F}=3.092$

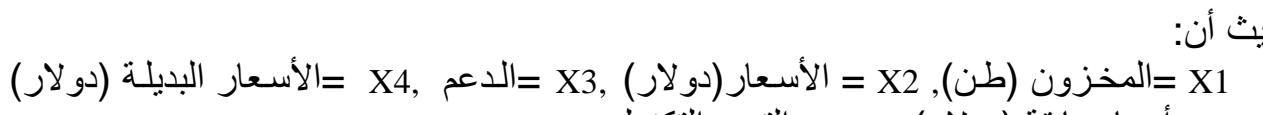

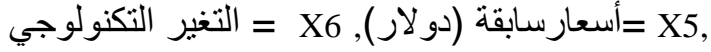




$$
\begin{array}{ll}
\log \mathrm{Y}=3.263+ & \begin{array}{c}
0.26 \log \mathrm{X} 3 \\
\mathrm{~T}= \\
(2.23)
\end{array} \\
R^{2}=44.60 \% & R^{-2}=34.90 \% \\
\mathrm{~F}=10.47 &
\end{array}
$$

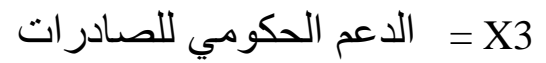

الصنادر ات من القمح (طن) =Y

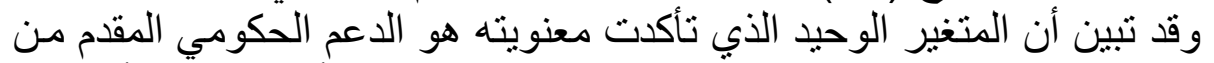

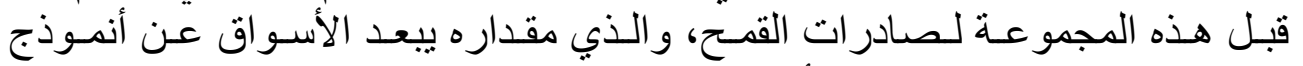

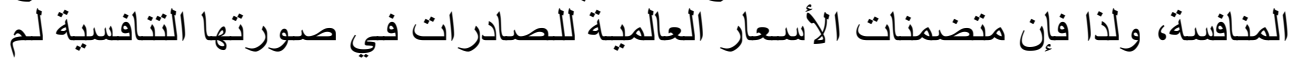

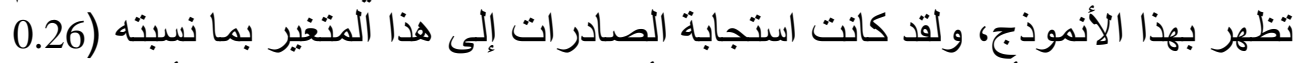

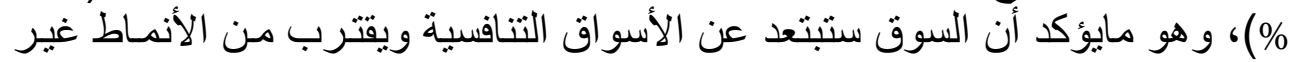

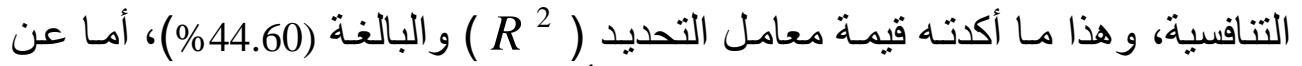
قيمة (Beta) فقد بلغت (0.66)، وتشير إلى الأهمية النسبية للمتغير المستقل (الدعم

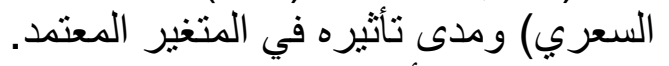

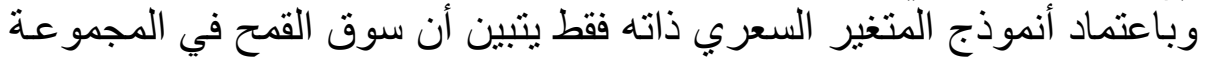

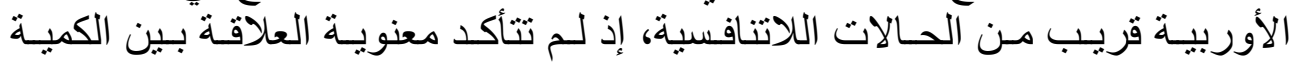

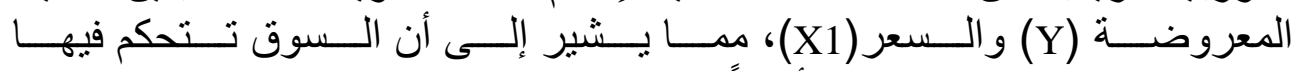
متغير ات لا سعرية، ويؤكد ذلك أيضاً قيمة معامل التحديد، إذ كانت (X1) (1.53 \% ) . $\log \mathrm{Y}=2.796+0.108 \mathrm{X} 1$

$\mathrm{T}=$ $(0.14)$

$\mathrm{R}^{2}=1.53$ $\mathrm{R}-2=1.00 \%$

\section{ع - ع استر اليا}

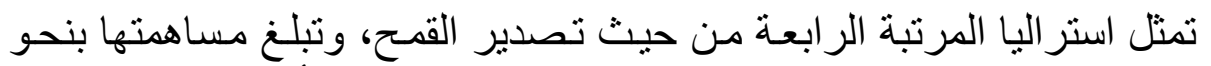

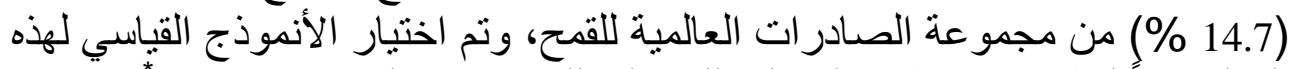

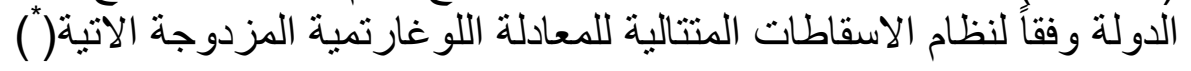

$$
\begin{gathered}
\operatorname{Logy}=0.089+0.698 \log X 1-0.396 \log X 4+0.39 \log X 7 \\
(6.95) \quad(-4.82) \\
R^{2}=\begin{aligned}
90.92 \% \\
\text { F }=36.7
\end{aligned} \quad, \quad R^{-2}=88.45 \%
\end{gathered}
$$

( ) ( ) الأنموذج الكامل لصادر ات القمح الاستر الية $\log Y=-0.633+0.665 \log X 1-0.12 \log X_{2}+0.24 \log X_{3}-0.25 \log X_{4}+0.004 \log X_{5}$
(3.27)
$(-0.13)$
$(0.53)$
$(-1.65) \quad(0.01)$

$-0.04 \log \mathrm{X}_{6}+0.63 \log \mathrm{X}_{7}-0.09 \log \mathrm{X}_{8}-0.01 \log \mathrm{X}_{9}$

$\begin{array}{llll}(-0.19) & (0.87) \quad(-0.12) \quad(-0.02)\end{array}$ 
الإنتاج (طن) =X

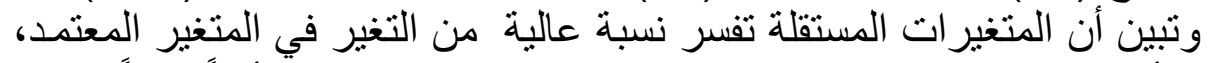

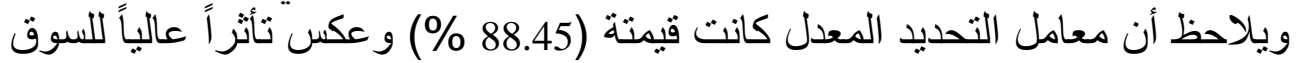

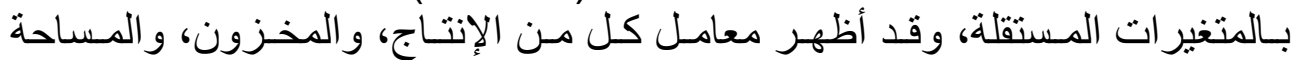

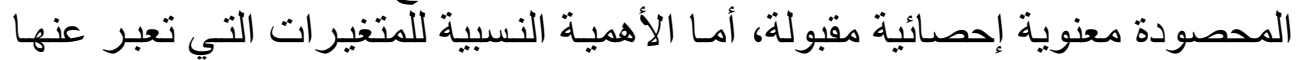

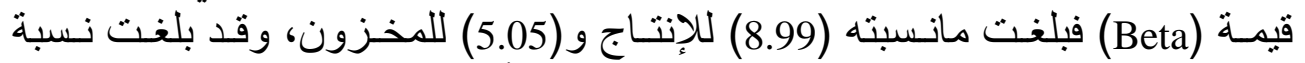

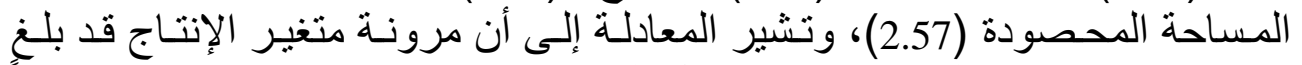

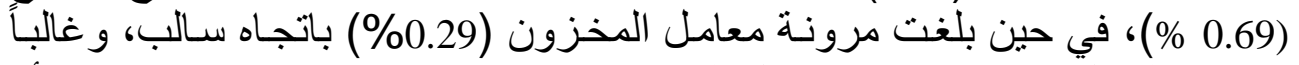

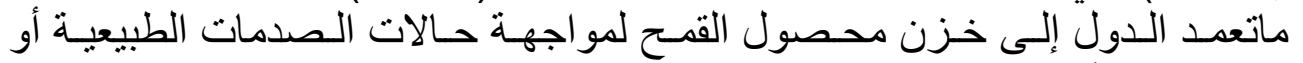

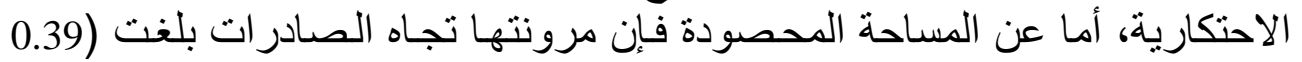

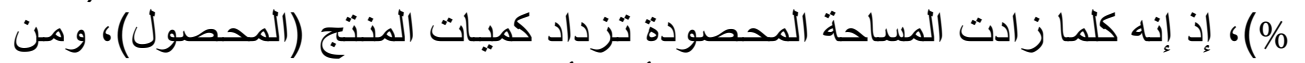

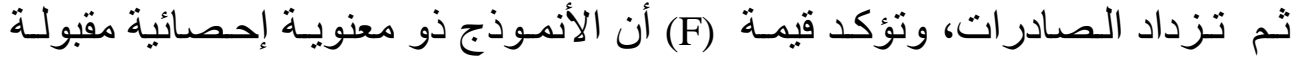
(36.7) ودلت على معنوية الأنموذج ككل، ويشير معامل التفسير المعدل إلى إلى أنى أن هذا

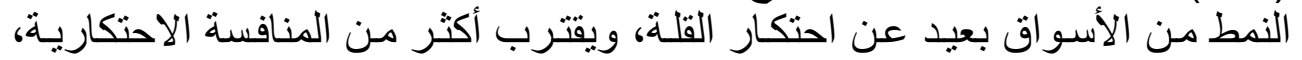

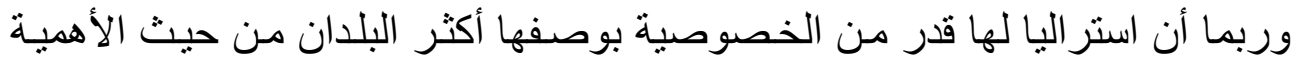

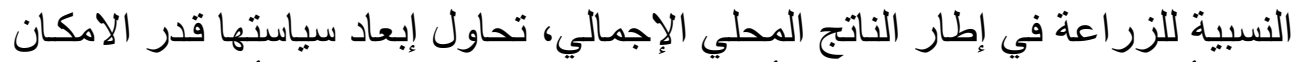

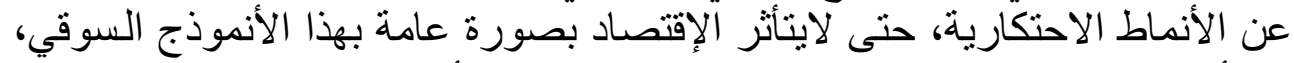

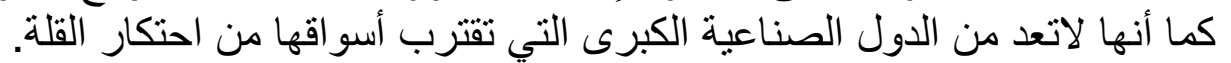

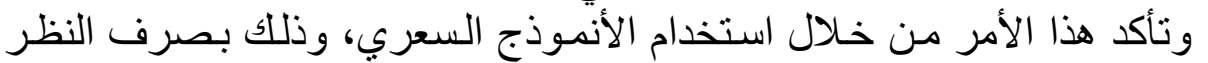

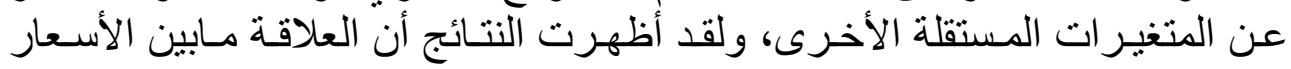

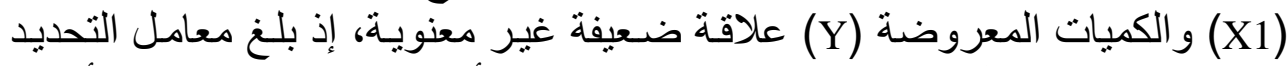

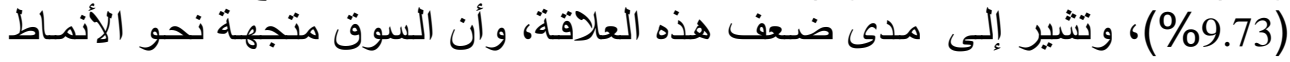

$$
\begin{array}{ll}
\log \mathrm{Y}=0.3900+0.4017 \mathrm{X}_{1} \\
\mathrm{~T}= & (1.18) \\
R^{2}=97.7 \% & R^{-2}=\% 29.9 \\
\mathrm{~F}=1.4 &
\end{array}
$$

غير الاحتكارية.

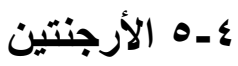

تعد الأرجنتين من الدول المنتجة و المصدرة للقمح، إذ إنها دخلت وفي الآونـة

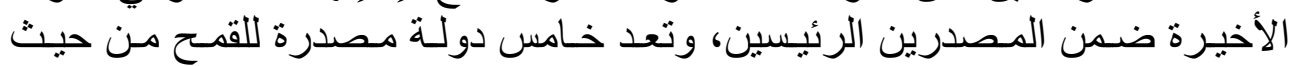

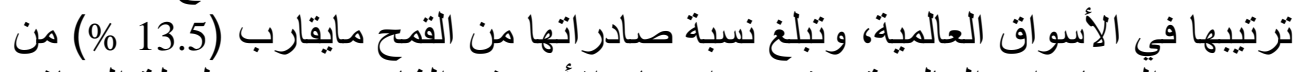

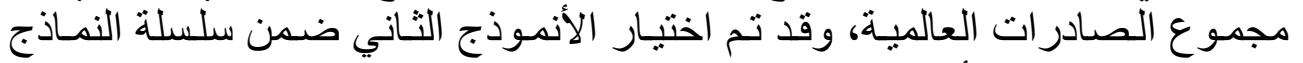

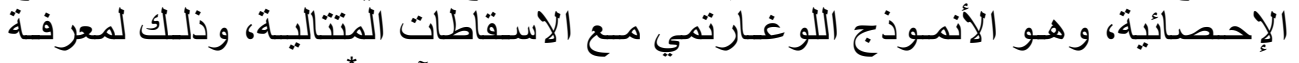

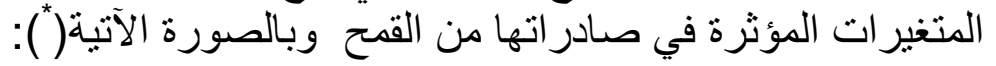

() الأنموذج الكامل لصادر ات القمح الارجنتينية $\log y=10.8-1.40 \log X_{1}+0.61 \log X_{2}-0.90 \log X_{3}-0.14 \log X_{4}$
$(-1.45)$
(1.26)
$(-1.89)$
$(-0.18)$ 


$$
\begin{aligned}
& \log \mathrm{Y}=6.295+0.262 \log \mathrm{X}_{6}-0.961 \log \mathrm{X}_{9} \\
& \mathrm{~T}= \\
& R^{2}=60.81 \% \quad R^{-2}=54.28 \%
\end{aligned}
$$

$$
\begin{aligned}
& \mathrm{F}=10.4
\end{aligned}
$$

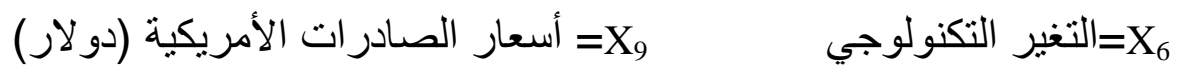

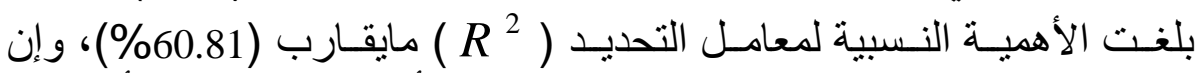

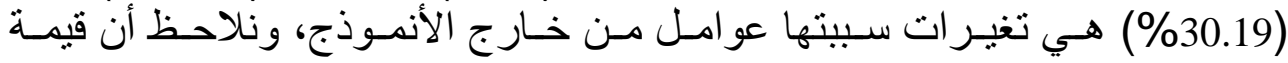

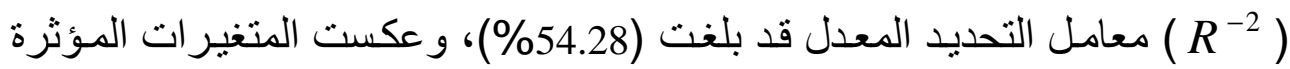

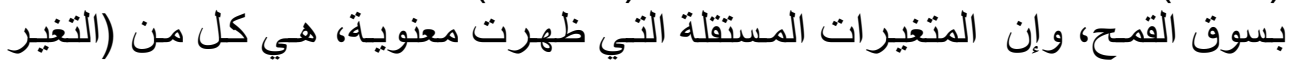

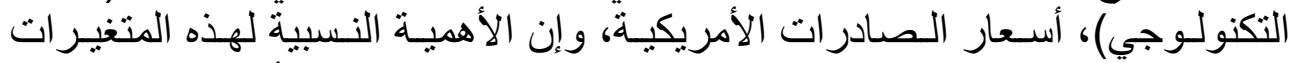

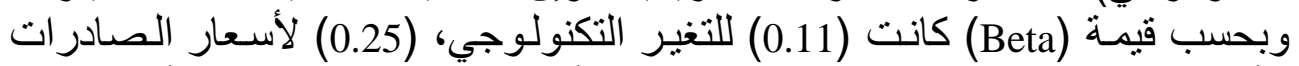

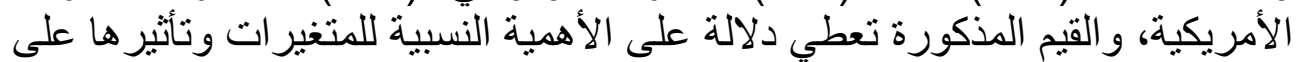

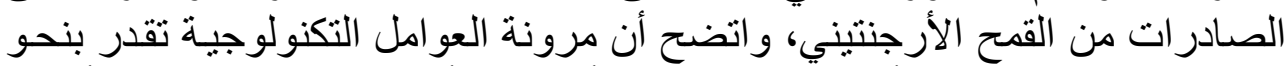

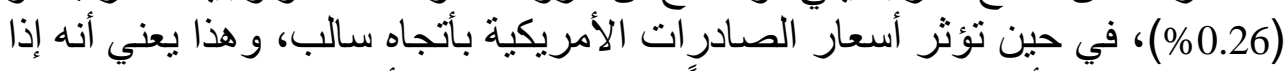

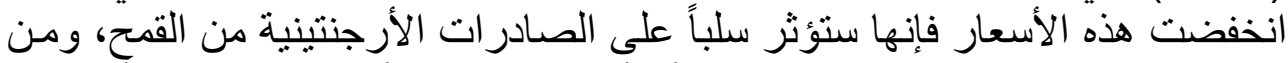

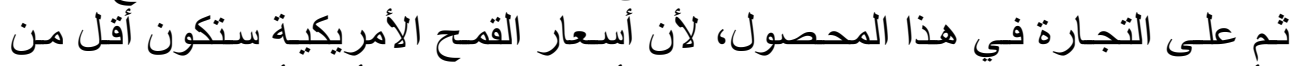

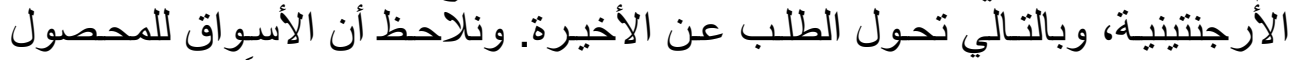

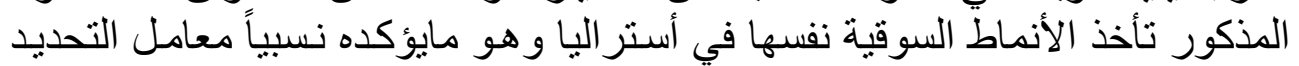

$$
\begin{aligned}
& \mathrm{Y}=-1.22+0.707 \log \mathrm{X}_{1} \\
& \mathrm{~T}=2.04 \\
& R^{2}=55.50 \% \quad R^{2}=44.33 \% \\
& \mathrm{~F}=4.1
\end{aligned}
$$

للعلاقة بين السعر و الكمية الذي بلغ (55.50\%).

•ـ السوق العالمي للقمح

\footnotetext{
$-1.55 \log \mathrm{X}_{5}+0.06 \log \mathrm{X}_{6}+0.37 \log \mathrm{X}_{7}+0.90 \log \mathrm{X}_{8}-0.001 \log \mathrm{X}_{9}$

$\begin{array}{lllll}(-2.06) & (0.50) & (0.36) & (-1.87) & (-0.01)\end{array}$

$R^{2}=87.3 \%$

$R^{-2}=64.3 . \%$

$\mathrm{F}=3.81$

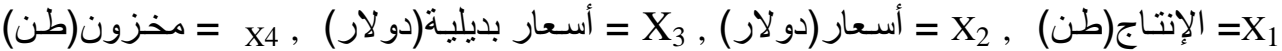

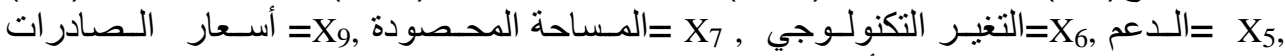
الامريكية (دولار) , X10=X الأسعار الَسابقة (دولار).
} 


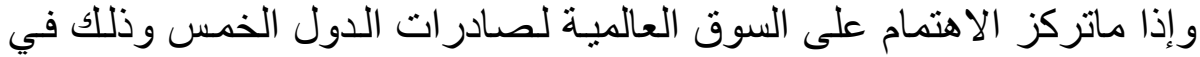

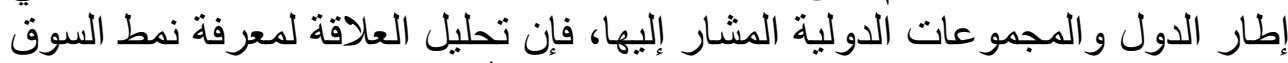
بصفتها التجميعية، قد أخذ شكل العلاقة الدالية الاتية ("):

$$
\begin{aligned}
& \mathrm{Y}=6.196+9.59 \mathrm{X}_{1}+0.28 \mathrm{X}_{2} \\
& \mathrm{~T}=\quad(3.23) \quad(2.47) \\
& R^{2}=48.41 \quad R^{-2}=39.81
\end{aligned}
$$

$\mathrm{F}=5.63$

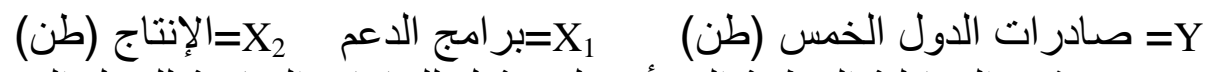

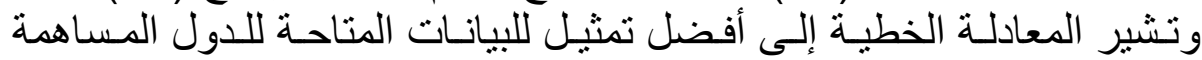

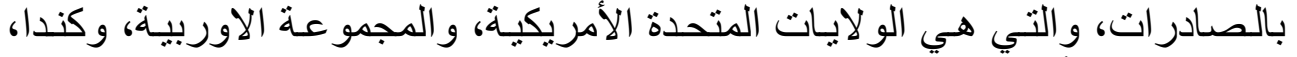

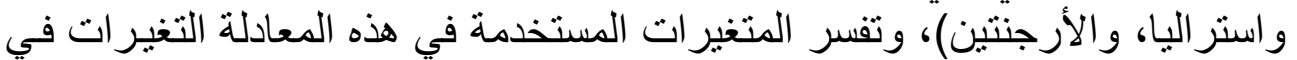

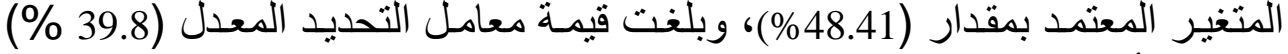

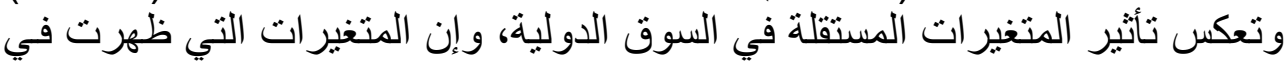

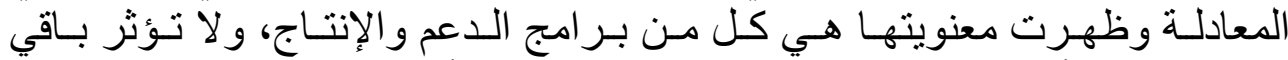

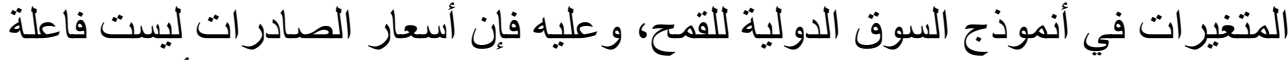

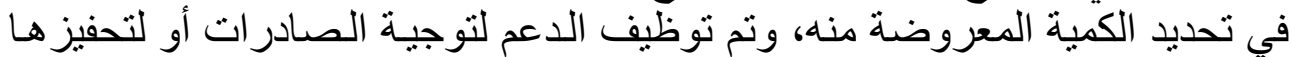

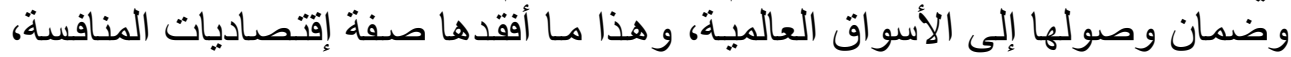

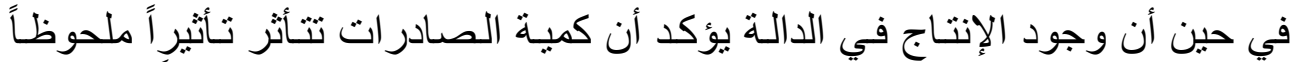

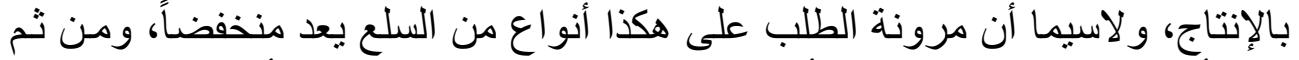

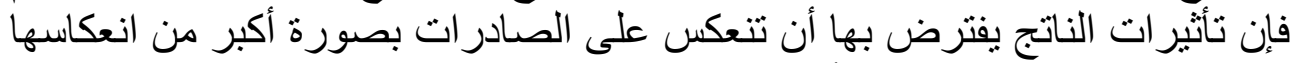

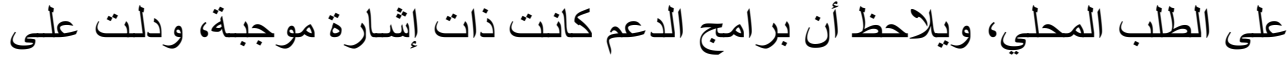

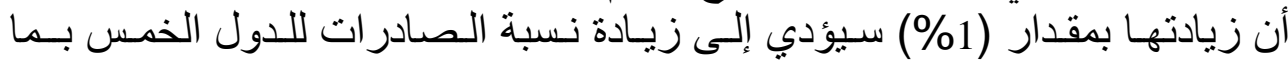

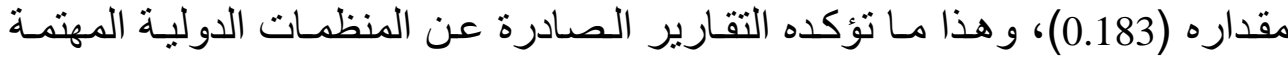

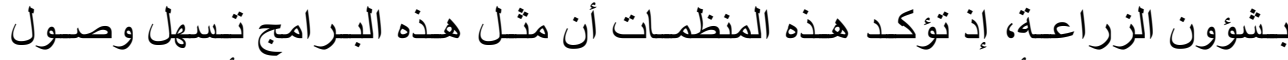

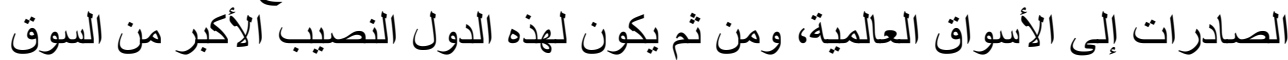

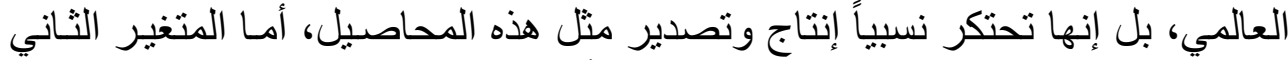

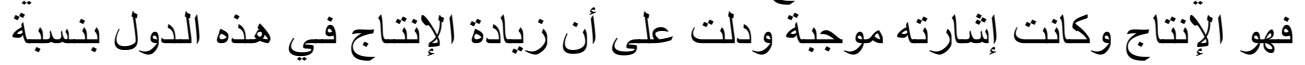

$$
\text { () الأنموذج الكامل لصادر ات القمح للدول الخمسة }
$$

$$
\begin{aligned}
& \mathrm{Y}=-7.24+0.33 \mathrm{X}_{1}+0.023 \mathrm{X}_{2}+0.043 \mathrm{X}_{3}+0.065 \mathrm{X}_{4}+0.034 \mathrm{X}_{5}+10.56 \mathrm{X}_{6} \\
& \begin{array}{lllll}
(1.64) & (0.23) & (-0.47) & (0.02) & (0.22)
\end{array} \\
& R^{2}=51.02 \% \quad R^{-2}=14.24 \% \\
& \mathrm{~F}=1.38
\end{aligned}
$$

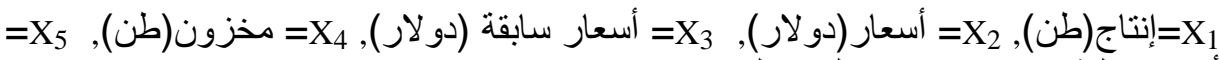

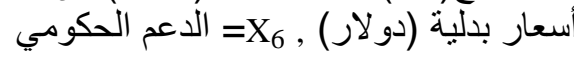


النجفي ورشاد [1A] هل ان أسواق القمح العالمية غير تتافسية؟...

(1\%) ستؤدي إلى زيادة الصـادر ات أو زيادة نسبتها في مجموع الصادر ات العالميـة

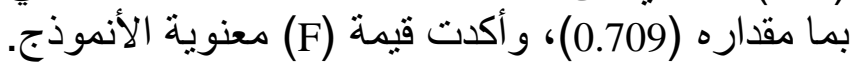

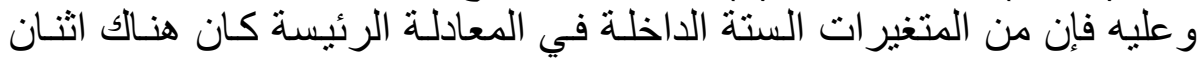

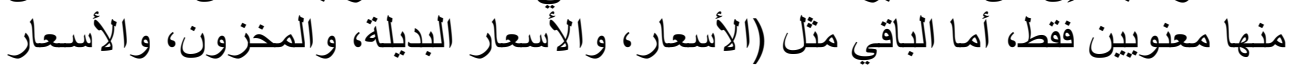

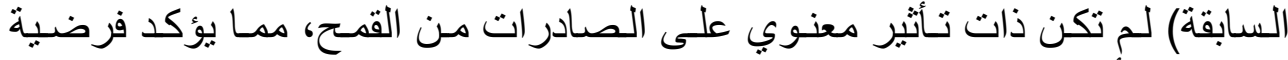

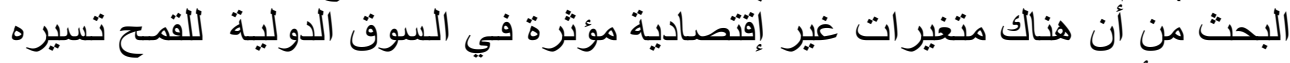
بحسب الأوضاع و الظروف لن السائدة.

\section{| الجدول المبول}

مقارنة معنوية المتغيرات المستقلة في الدول المصدرة الرئيسة للقمح

\begin{tabular}{|c|c|c|c|c|c|c|}
\hline العالمية & الأرجنتين & استراليا & الأجمورية & كندا & أمريكا & 1 \\
\hline \%39.81 & $\% 54.28$ & $\% 88.45$ & $\% 90.34$ & $\% 46.10$ & $\% 40.34$ & $R^{-2}$ \\
\hline 5.61 & 10.4 & 36.74 & 10.47 & 6.92 & 10.46 & $\bar{F}$ \\
\hline$\sqrt{ }$ & $x$ & $x$ & $\sqrt{ }$ & $x$ & $\sqrt{ }$ & الدعم الحكومي \\
\hline$\sqrt{ }$ & $x$ & $\sqrt{ }$ & $x$ & $\sqrt{ }$ & $x$ & الإنتاج \\
\hline$x$ & $x$ & $\sqrt{ }$ & $x$ & $x$ & $x$ & المخزون \\
\hline$x$ & $x$ & $x$ & $x$ & $x$ & $x$ & المساحة المحصودة \\
\hline$x$ & $\sqrt{ }$ & $x$ & $x$ & $x$ & $x$ & الأسعار البديلة \\
\hline$x$ & $x$ & $x$ & $x$ & $x$ & $x$ & الأسعار \\
\hline$x$ & $x$ & $x$ & $x$ & $x$ & $x$ & الأسعار السـابقة \\
\hline$x$ & $\sqrt{ }$ & $x$ & $x$ & $x$ & $x$ & التكنولوجيا \\
\hline$x$ & $\sqrt{ }$ & $x$ & $x$ & $x$ & $x$ & الأمريكية \\
\hline
\end{tabular}

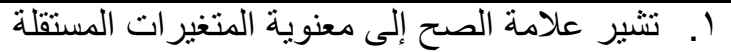

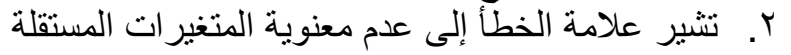

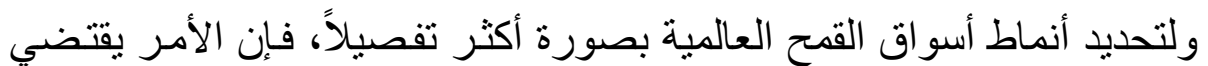

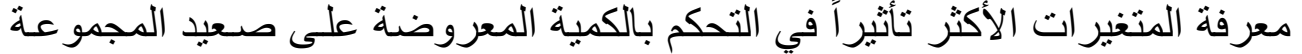

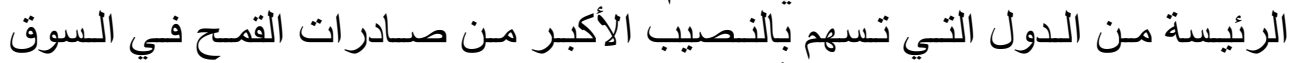

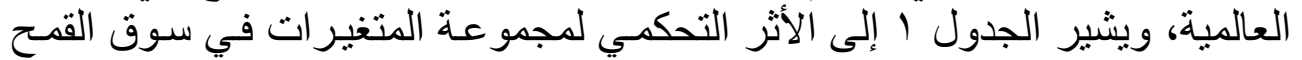
الاجها

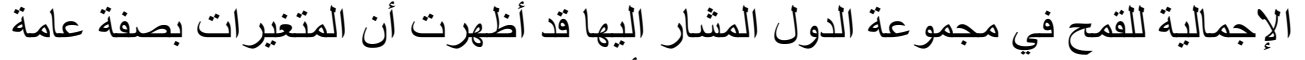

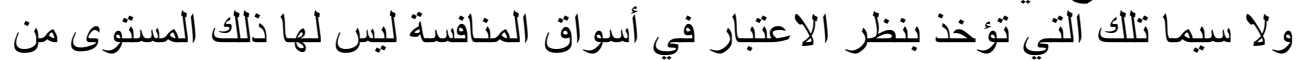

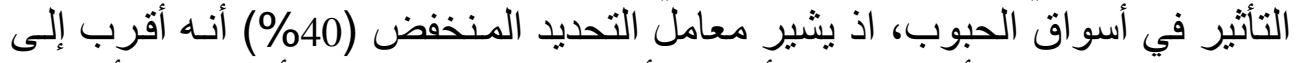

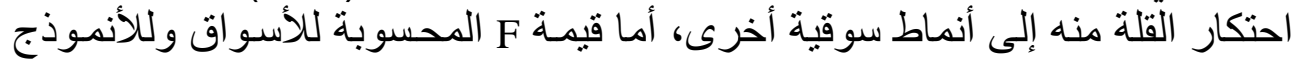




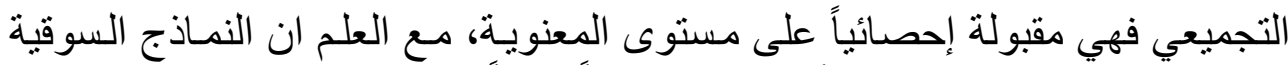

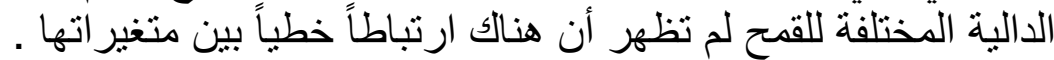

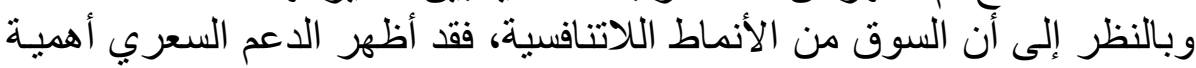

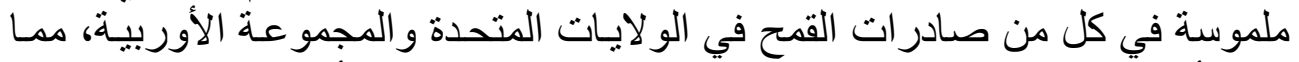

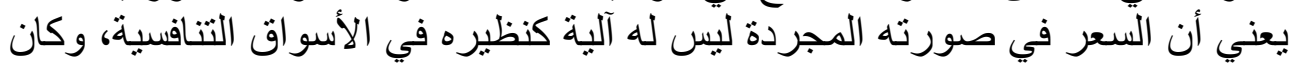

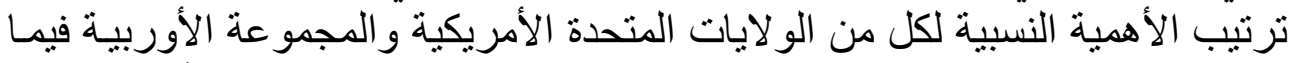

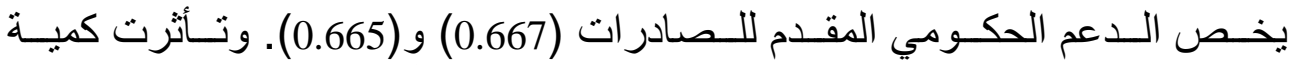

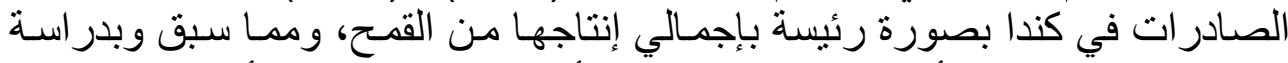

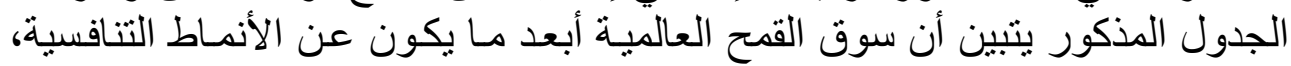

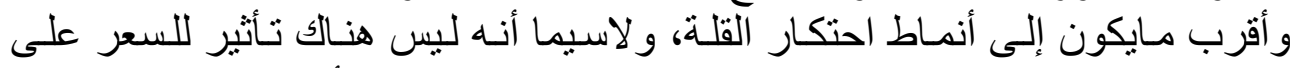

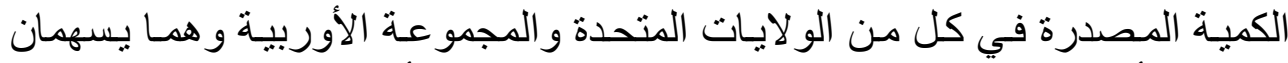
بالجزء الأكبر من صنادر ات القمح، في حين كانت هناللك تأثير ات منو اضعة في كندات التها.

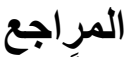 \\ أولاًا-المراجع بالاجغة الماجة العربية}

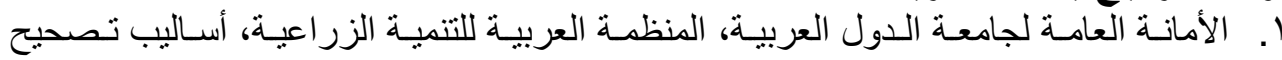

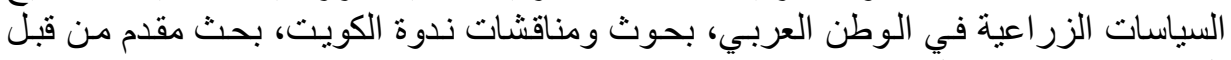

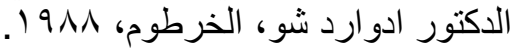

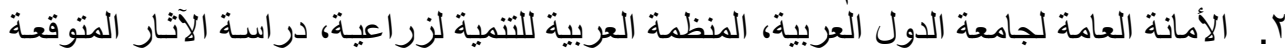

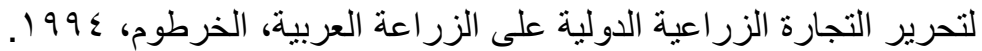

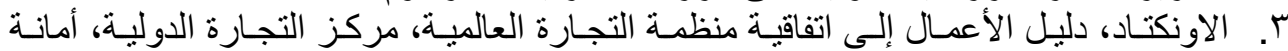

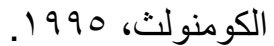

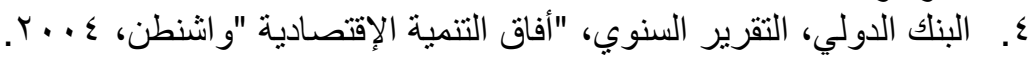

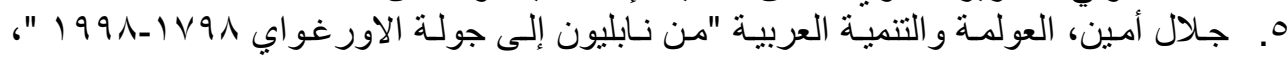

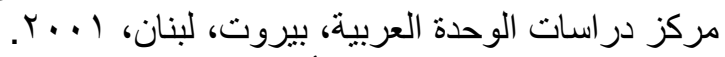

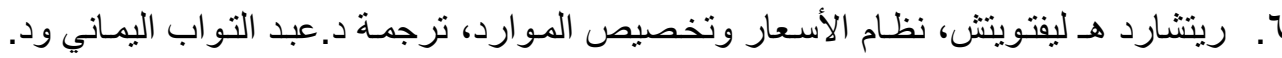

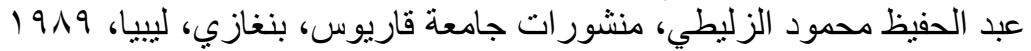

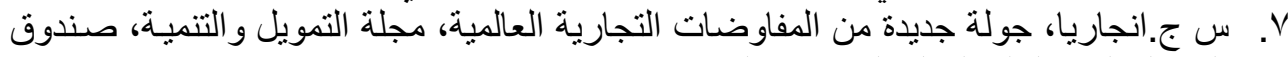

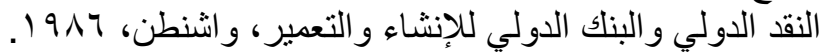

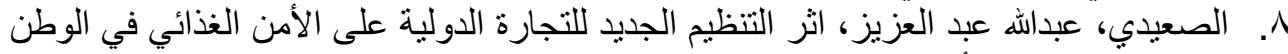

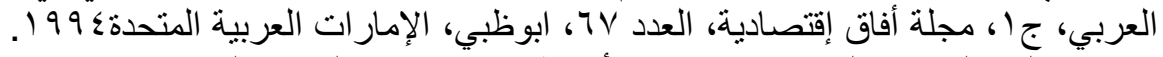

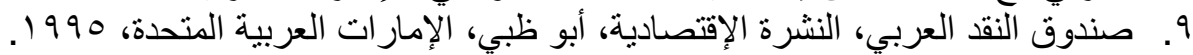

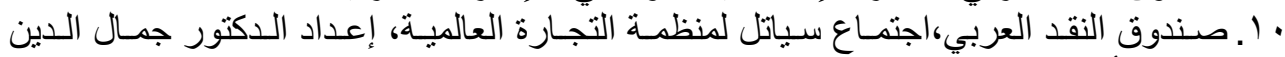

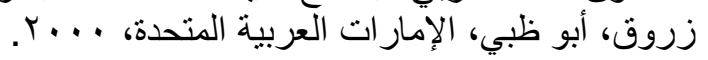

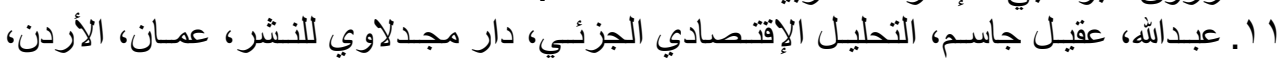
.1999

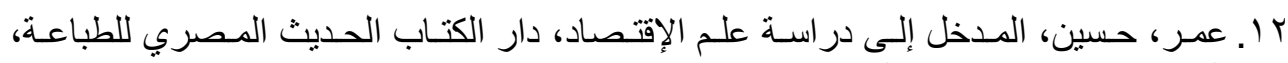

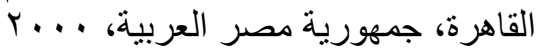

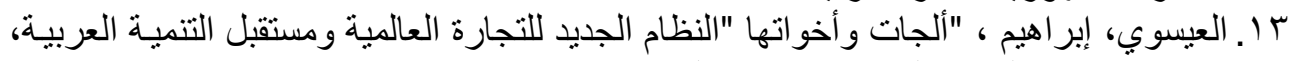

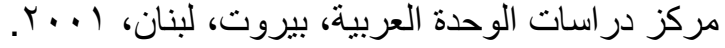




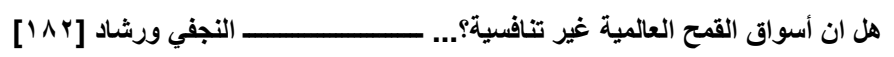

ع ( ـ فاندانا شيفا، اتفاقية هنظمة التجارة العالمية الخاص بالزر اعة، ترجمة خالد الفيشاوي، زي نت

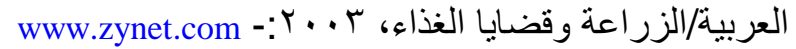

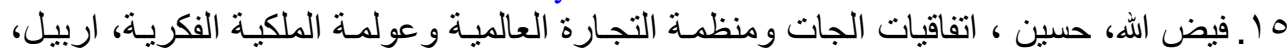

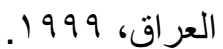

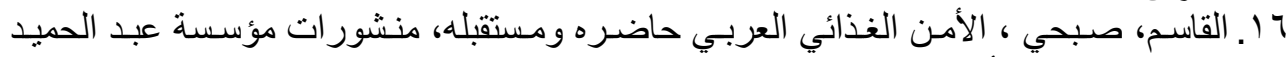

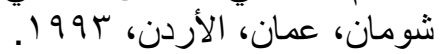

V V ا. كراجة، عبد الحليم وآخرون، مبادئ الإقتصاد الجزئي، دار الصفاء للطباعة و النشر و التوزيع،

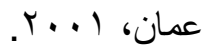

1 1 أكمال، علاء، الجات ونهب الجنوب ـالجات وتناقضات الكبار، الحوار المتمدن، لجان إحياء

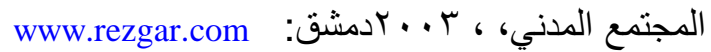

9 اـ اللجنة الإقتصادية والإنية الاجتماعية لغربي أسيا "الاسكو ا"، أوراق موجزة، المفاوضات حول قضايا

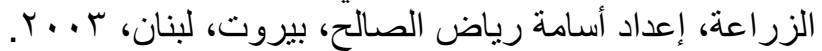

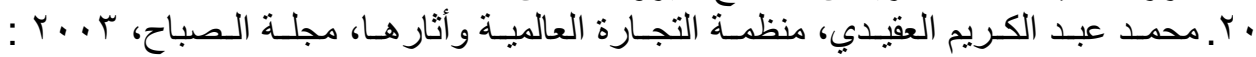
www.alsabaah.com

آ إ. محمود الأشرم، إنتاج الحبوب و الأمن الغذائي في الوطن العربي، مجلة المستقبل الإقتصادي،

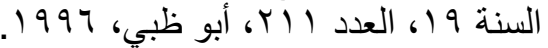

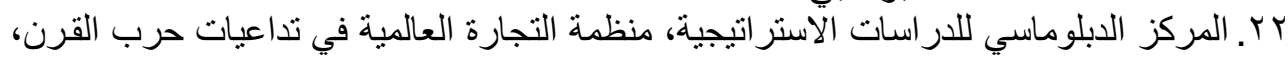

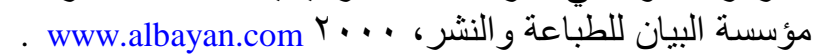

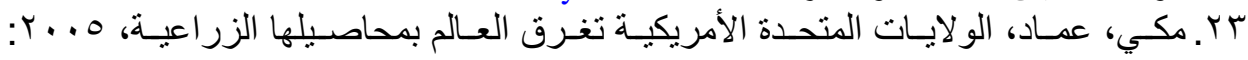
. Www.IPS.com

ع r. منظمة الأغذية و الزر اعة للأمم المتحدة "الفاو"، الأوضـاع الر اهنـة للأغذية في العـالم، الدورة

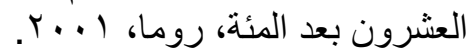

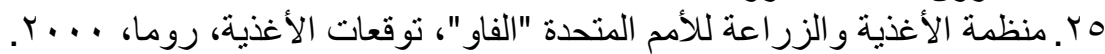

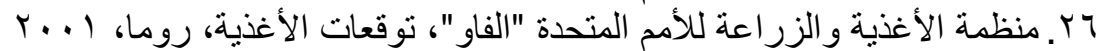

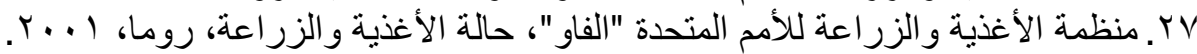

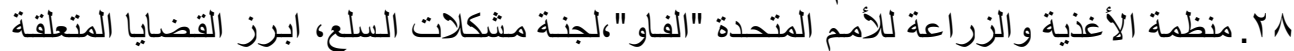

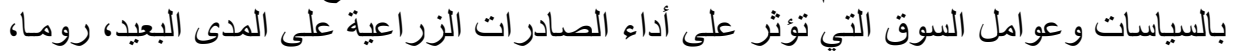
r...r

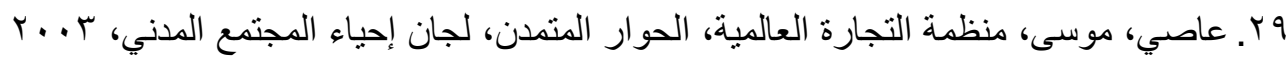
www.mowaten.org و www.rezgar.com

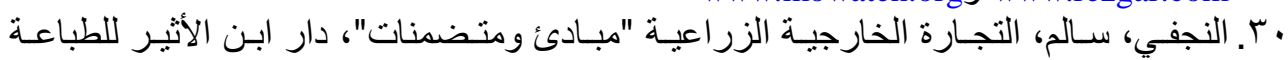

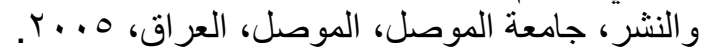

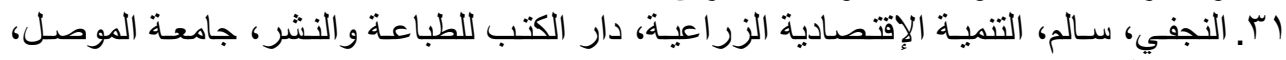

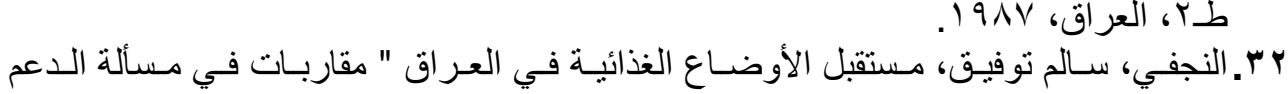

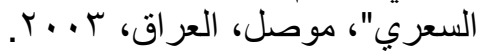

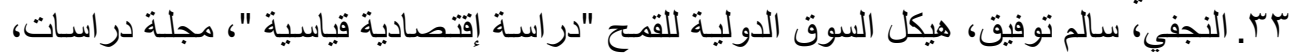

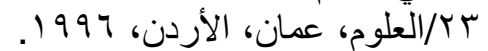

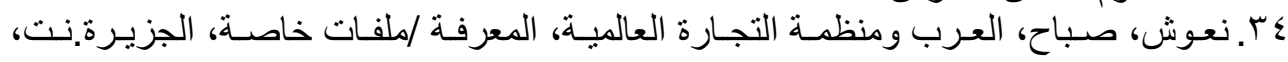
r...

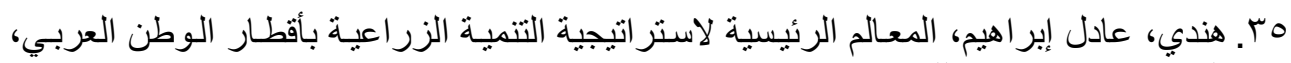

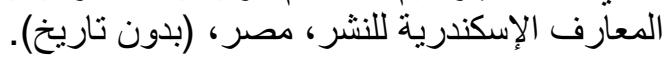
דr. 


\section{ثانياً. المراجع باللغة الأجنبية}

1. Anna.Koutsoyiannis, Modren Microeconomics, the Macmillan Press Ltd, London, 1988.

2. Bernard Hoekman and Kym Anderson, Developing Country Agriculture and The New Trade Agenda,World bank, Washington D.C.,And Center for International Economic Studies ,University of Adelaide 5005,Australia, 1999.

3. bhoekman @ worldbank .org \& kanderson@economics.adelaide.edu.au

4. David Orden\&Others, Liberalizing Agricultural Trade and Developing Countries, Global Policy Program, Carnegie Endowment for International Peace, Washington D.C, 2002.

5. Kyle Bagwell \& Robert W.Staiger, Strategic Trade Competitive Industries and Agricultural Trade Disputes, Columbia University \& University of Wisconsin\& NBER, 2000.

6. UNCTAD/WTO, Market Analysis, International Trade Centre, UN. www.UNCTAD.ORG, 2003.

7. Warren Vieth, US Exports Misery to Africa with Farm Bill, Los Angeles Times Monday.www.commondreams.org, 2002 .

8. www.carnegie.org 